\title{
NATIONAL BUREAU OF STANDARDS REPORT 4414
}

\author{
PROJECTS and PUBLICATIONS \\ of the \\ APPLIED MATHEMATICS DIVISION
}

A Quarterly Report
July through September 1955

FOR OFFICIAL DISTRIBUTION

\section{INBS}

U. S. DEPARTMENT OF COMMERCE

NATIONAL BUREAU OF STANDARDS 


\section{U. S. DEPARTMENT OF COMMERCE}

Sinclair Weeks, Secretary

NATIONAL BUREAU OF STANDARDS

A. V. Astin, Director

\section{THE NATIONAL BUREAU OF STANDARDS}

The scope of activities of the National Bureau of Standards is suggested in the following listing of the divisions and sections engaged in technical work. In general, each section is engaged in specialized research, development, and engineering in the field indicated by its title. A brief description of the activities, and of the resultant reports and publications, appears on the inside of the back cover of this report.

Electricity and Electronics. Resistance and Reactance. Electron Tubes. Electrical Instruments. Magnetic Measurements. Process Technology. Engineering Electronics. Electronic Instrumentation. Electrochemistry.

Optics and Metrology. Photometry and Colorimetry. Optical Instruments. Photographic Technology. Length. Engineering Metrology.

Heat and Power. Temperature Measurements. Thermodynamics. Cryogenic Physics. Engines and Lubrication. Engine Fuels.

Atomic and Radiation Physics. Spectroscopy. Radiometry. Mass Spectrometry. Solid State Physics. Electron Physics. Atomic Physics. Nuclear Physics. Radioactivity. X-rays. Betatron. Nucleonic Instrumentation. Radiological Equipment. AEC Radiation Instruments.

Chemistry. Organic Coatings. Surface Chemistry. Organic Chemistry. Analytical Chemistry. Inorganic Chemistry. Electrodeposition. Gas Chemistry. Physical Chemistry. Thermochemistry. Spectrochemistry. Pure Substances.

Mechanics. Sound. Mechanical Instruments. Fluid Mechanics. Engineering Mechanics. Mass and Scale. Capacity, Density, and Fluid Meters. Combustion Controls.

Organic and Fibrous Materials. Rubber. Textiles. Paper. Leather. Testing and Specifica. tions. Polymer Structure. Organic Plastics. Dental Research.

Metallurgy. Thermal Metallurgy. Chemical Metallurgy. Mechanical Metallurgy. Corrosion.

Mineral Products. Porcelain and Pottery. Glass. Refractories. Enameled Metals. Concreting Materials. Constitution and Microstructure.

Building Technology. Structural Engineering. Fire Protection. Heating and Air Conditioning. Floor, Roof, and Wall Coverings. Codes and Specifications.

Applied Mathematics. Numerical Analysis. Computation. Statistical Engineering. Mathematical Physics.

Data Processing Systems. Components and Techniques. Digital Circuitry. Digital Systems. Analogue Systems.

Cryogenic Engineering. Cryogenic Equipment. Cryogenic Processes. Properties of Materials. Gas Liquefaction.

Radio Propagation Physics. Upper Atmosphere Research. Ionospheric Research. Regular Propagation Services.

Radio Propagation Engineering. Frequency Utilization Research. Tropospheric Propagation Research.

Radio Standards. High Frequency Standards. Microwave Standards.

- Office of Basic Instrumentation

Office of Weights and Measures 


\title{
NATIONAL BUREAU OF STANDARDS REPORT NBS PROJECT \\ NBS REPORT \\ NAML \\ 4414
}

\author{
PROJECTS and PUBLICATIONS \\ of the \\ APPLIED MATHEMATICS DIVISION
}

July through September 1955

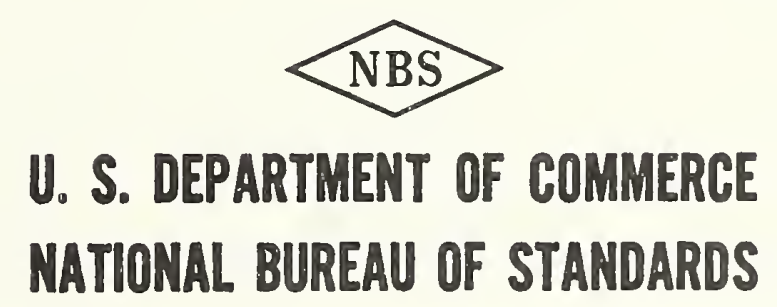

The publication, repeinting, unless permission is obtalned 25, D.C. Such pormission li cally prepared if that agen

Approved for public release by the director of the National Institute of Standards and Technology (NIST) on October 9, 2015 iprohibltod Washington ioen spocifts own use. 


\title{
APPLIED MATHEMATICS DIVISION
}

July 1 through september 30, 1955

TECHNICAL ADVISORY COMMITTEE

\author{
David BlackweIl, Howard University \\ Edward U. Cond on \\ Mark Kac; Cornell University
}

\author{
Philip M. Morse, Massachusetts \\ Institute of Technology \\ Mina S. Rees, Hunter College
}

A. H. Taub, University of Illinois

\section{DIVISION OFFICE}

\author{
Edward W, Cannon, Ph.D., Chief \\ Franz L. Alt, Ph.D., Assistant Chief \\ olga Taussky-Todd, Ph.D., Consultant \\ W. J. Youden, Ph.D., Consultant \\ Myrtle R. Kellington, M.A., Technical Aid \\ Luis 0. Rodriguez, M. A., Chief Clerk \\ Yates S. Sladen, Assistant Chief Clerk \\ Mary E. McKinley, Secretary \\ Esther L. Turner, Secretary
}

NUMERICAL ANALYS IS SECTION John Todd, B.S., Chief

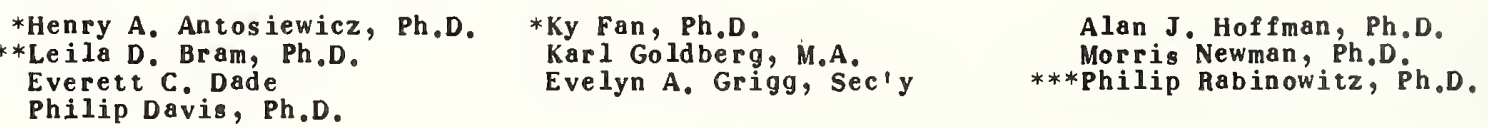

C.OMPUTATION LABORATORY Milt on Abramowitz, Ph.D., Chief

Irene A. Stegun, M.A., Assistant Chief

Joseph Bram, Ph.D.

Hans O. Bremer, B.A.

William F. Cahill, M.S.

Ruth E. Capuano

Anne C. Bruno, B.A.

Mary M. Dunlap, B.S.

Anne M. Futterman, B.A.

Jane C.. Gager

Billie R. Gill, M.S.

Elizabeth F. Godefroy

William G. Hall, B.S.

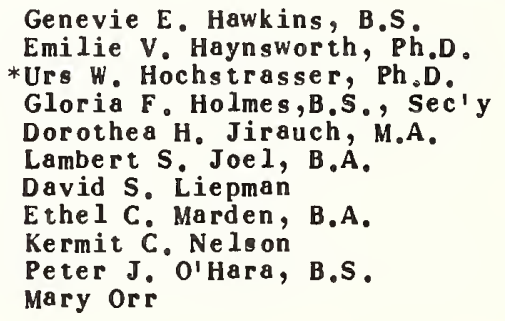

Genevie E. Hawkins, B.S. Emilie V. Haynsworth, Ph,D.

*Urs W. Hochstrasser, Ph,D. Gloria F. Holmes, B.S., Sec'y Dorothea H. Jirauch, M.A. Lambert S. Joe 1, B.A. David S. Liepman

E thel C. Marden, B.A. Kermit $C$. Nelo on Peter J. O'Hara, B.S. Mary or $\mathbf{r}$

Maxine L. Paulsen, B.S. Sally T. Peavy, B.S. B. Stanley Prusch Id a Rhodes, M.A. Philip J. Walsh, B.S. Bertha H. Walter Joseph H. Wegstein, M.S. Donald F. Wehn, B.A. Richard $\dot{G}$. Williams, M.S. Ruth Zucker, B.A.

\section{STATISTICAL ENGINEERING LABORATORY Churchill Eisenhart, Ph.D., Chief}

Joseph M. Cameron, M.S., Assistant Chief

Robert.C. Burton

Marion T. Carson

Willard $H$. Clatworthy, Ph.D.

Lola S. Deming, M. A.

Mary L. Epling, B.S.
Seymour Geisser, Ph.D.

Lela J. Hamilton, Sec'y

Forest L. Miller, Jr.

Julius Lieblein, Ph.D.
Mary G. Natrella, B.A.

Hugh M. Pettigrew

* Paul N. Somerville, Ph.D.

Carolyn Yick, Sec'y Marvin Zelen, M. A.

\section{MATHEMATICAL PHYSICS SECTION Robert F. Dressler, Ph.D., Chief}

Peter Chiarulli, Ph.D.
John W. Cooper, B.S.
Leon Feldman, B.A. $\begin{array}{ll}\text { *Peter Henrici, Ph.D. } & \text { Edith N. Reese, B.A. } \\ \text { *Fritz Oberhettinger, Ph.D. } & \text { Lillian Sloane, Sec'y }\end{array}$ 


\section{CONTENTS}

Page

Status of Projects* as of September $30,1955 . . .1$

Numerical Analysis... . . . . . . 1

Mathematical Tables . . . . . . . 10

Probability of Mathematical Statistics. . . 15

Mathematical Physics........ 18

Mathematical and Computational Services . . . 23

Statistical Engineering Services. . . . . 39

Application of SEAC. . . . . . . . . 41

Lectures and Symposia .......... 43

Publication Activities. . . . . . . . 45

* On ly unclassified projects are included in this report. 


\section{Status of Projects}

September 30,1955

\section{NUMERICAL ANALYSIS}

\section{RESEARCH IN THEORIES OF DISCRETE STRUCTURES Task 1100-10-5116/56-159}

Origin: NBS

Sponsor: Office of Naval Research

Authorized $9 / 30 / 55$

Manager: 0 . Taussky-Todd

Objective: To conduct basic research in branches of pure and applied mathematics, especially in problems of discrete structures, including algebra and number theory, related to numerical analysis.

Background: Theories of discrete structures have become increasingly important in a number of applied fields, as a result of the existence of high-speed computers, which make it possible to perform the usually very long calculations occurring in these areas.

Status: NEW. 0. Taussky-Todd and M. Newman extended their results concerning unimodular integral circulants from prime power orders to arbitrary orders. A by-product of this was the solution of a problem in elementary number theory. This has been submitted to the problem section of the Dutch journal, "Wiskundige Opgaven."

o. T. Todd, H. P.F. Swinnert on-Dyer (from Cambridge, England), and $M$. Newman are using SEAC for computing units and the class number of cubic cyclic algebraic number fields of prime conductor. This is to check and extend a table computed by Mr. Swinnerton-Dyer previously on EDSAC, at Cambridge, England.

In connection with the work of this task, M. Newman, together with I. Reiner (presently at the Institute for Advanced Study, Princeton), proved the following theorem: Let $k$ be a positive integer, and let $k=r+s$ be some fixed partition of $k$ into positive integers $r, s$. Let $M$ be a kxk unimodular matrix. of rational integers, partitioned as ( $\left(\begin{array}{c}A B \\ C D\end{array}\right)$, where $A$ is an rxr matrix, B an rxs matrix, C an sxr matrix and D an sxs matrix. Let $T$ be the multiplicative group of matrices $M$, and $T(m, n)$ the subgroup of $\Gamma$ characterized by $B \equiv O(\bmod m), C \equiv O(\bmod n)$, where $m$ and $n$ arenon-zero rational integers. Then if $(m, n)=1$ and $\Delta$ is any subgroup of $\Gamma$ containing $\Gamma(m, n), \Delta=\Gamma\left(m_{1}, n_{1}\right)$ where $m_{1} \mid$ n and $n_{1} \mid n$. If $(m, n)>1$ there are subgroups of $\Gamma$ containing $\Gamma(m, n)$ which are not of this form. A manuscript has been prepared. matrices.

O. T. Todd continued research on the eigenvalues of positive

0. T. Todd, Ky Fan and J. Todd discussed the two-dimensional discrete analog of the Wirtinger inequality. The only new feature occurring is the fact that equality is obtained if and only if the variable vector is a linear combination of a certain set of four (n2) vectors. As another by-product of their work on the Wirtinger inequality, 
Ky Fan, O.T.Todd and J. Todd obtained an algebraic proof of the isoperimetric property of polygons. The usual proofs are geometrical or analytical. The present proof, after reducing the problem to the convex equilateral case, begins by showing that for any $n(\geqslant 3)$ complex numbers, $z_{1}, z_{2}, \ldots, z_{n}$, we have

$$
\sum_{j=1}^{n}\left|z_{j}-z_{j+1}\right|^{2} \geq 2 \tan \frac{\pi}{n} \mathfrak{J} \sum_{j=1}^{n} z_{j} z_{j+1}
$$

(where $z_{n+1}=z_{1}$ ), and that there is equality if and only if

$$
\mathbf{z}=\alpha \exp (2 \pi \mathrm{i} \mathbf{j} / \mathrm{n})+\beta, \quad \mathrm{j}=1,2, \ldots, \mathrm{n}
$$

If the $z^{\prime}$ s are the vertices of an equilateral polygon this gives $L^{2} \geq 4 n \mathbf{t a n}^{-1} F$, where $L$ is the perimeter and $F$ the area.

K. Goldberg with $E$. Dade investigated certain linear associative algebras. These algebras are characterized by having a basis of incidence matrices whose sum is the matrix of $1 / \mathrm{s}$. The results have been applied to the problem in graph theory mentioned in the preceding quarterly report. K. Goldberg continued his work on bounds and asymptotic behavior of the coefficients in the series for $\log e^{x} y$.

Publications:

(1) On a generalization of the normal basis in abelian algebraic number fields. M. Newman and O. Tausky-Todd. To appear in Communications on Pure and Applied Mathematics (New York University).

(2) A note on group matrices. 0. Taussky-Todd. To appear in the Proceedings of the American Mathematical Society.

(3) Power series for $\log \left(\mathrm{e}^{\mathrm{x}}, \mathrm{ey}^{\mathrm{y}}\right)$. K. Goldberg. To appear in the Duke Journal of Mathematics.

(4) The number of absolute points of a correlation. A. Hoffman, M. Newman, E. Straus, and 0 . Taussky. To appear in the Pacific Journal of Mathematics.

(5) Some computational problems in algebraic number theory. o. Taussy. To appear in the Proceedings of the American Mathematical Society Sixth Symposium on Applied Mathematics, held at Santa Monica, California, August 1953.

(6) Bounds and asymptotic behavior of the coefficients in the series $\log \left(e^{\mathrm{X}} \mathrm{e}^{\mathrm{y}}\right)$. K. Goldberg. In manuscript.

(7) Unimodular circulants. 0. Tausky-Todd. To appear in the I. Schur Memorial Volume, Mathematische Zeitschrift.

(8) Algebraic equations satisfied by roots of natural numbers. E. G. Straus (University of California at Los Angeles) and O. Taussy. To appear in Pacific Journal of Mathematics.

(9) Pairs of Matrices with property L,II. T. S. Motzkin and O.Taussky-Todd. To appear in Transactions of the American Mathematical Society.

(10) Generation and testing of pseudo-random numbers. O. Taussky-Todd. Submitted to a technical journal.

(11) An algebraic proof of the isoperimetric property of polygons. Ky Fan, olga Taussky and $J$. Todd. To appear in the Journal of the Washington Academy of Sciences. 


\section{RESEARCH IN NUMERICAL ANALYSIS AND RELATED FIELDS}

Task 1101-10-1104/55-55

Origin: NBS

Managers: J. Todd, P. Davis

Full task description: July-Sept 1954 issue, p.
Authorized $8 / 13 / 54$ Revised $8 / 29 / 54$

Status: CONTINUED. H. A. Antosiewicz has continued his investigation of Lyapunov's second method for the stability of solutions of systems of ordinary differential equations. He has obtained necessary and sufficient conditions for stability, simple and asymptotic, uniform and non-uniform, which are not included in the most recent results obtained by the Russian school.

P. Davis and Ky Faz have studied certain inequalities in normed linear spaces and their applications to problems of interpolation and approximation in real and complex variables. Let $\left\{f_{n}\right\}$ be a sequence in a normed linear space $X$ and let $\varnothing \in X^{*}$. Necessary and ${ }^{n}$ sufficient conditions that each of the following five relations hold have been derived:

$$
\begin{aligned}
& \text { I. }\left|\varnothing\left(\mathbf{f}_{n}\right)\right| \leq{ }_{n} \quad(n=1,2, \ldots) \text { implies } \varnothing=0 . \\
& \text { II. } \quad \lim _{n \rightarrow \infty} \varnothing\left(f_{n}\right)=0 \text { implies } \varnothing=0 . \\
& \text { III. }\left|\varnothing\left(f_{n}\right)\right| \leq a \quad(n=1,2, \ldots) \text { implies }\|\varnothing\| \leq \rho . \\
& \text { IV. }\left|\varnothing\left(f_{n}\right)\right| \geq 1 \quad(n=1,2, \ldots) \text { implies }\|\varnothing\| \geq \rho . \\
& \text { V. }\left|\varnothing\left(f_{n}\right)-a_{n}\right| \leq o_{n} \quad(n=1,2, \ldots) \quad\|\varnothing\| \leq \rho \text { is consistent. }
\end{aligned}
$$

Conditions I,II, and III have been studied in considerable detail and theorems of Paley-Wiener type have been obtained. Applications of these general results were made to L spaces over the real line and to certain Hilbert spaces of complex analytic functions. Theorems on approximation with coefficients restricted in size have been obtained. Applications have also been made to the theory of conformal kernel functions of the Bergman and Szegö type and to uniqueness theory for asymptotic expansions in the sense of Poincaré.

$P$. Davis carried out some further checks on the abscissae and weights for Gaussian quadratures of high order. determinants.

E. Haynsworth continued her program of research on bounds for

U. W. Hochstrasser studied the problem of improving the speed of convergence of over-relaxation by inverting submatrices of the coefficient matrix of the system of linear equations.

T. Kato has prepared a code for a new SEAC demonstration problem, which also provides a new test for random numbers. This is the classical problem of the gambler's ruin.

J. Gager completed a code to find the unique representation of a given prime of the form $4 K+1$ as a sum of two squares. The time for a ten digit prime is less than a minute.

J. Todd had discussed previously, theoretically and experimentally, the system of linear algebraic equations obtained by discretization of equations of the form $U_{x x}+U_{y y}=k U$. The case of a rectangle, in cartesian coordinates, was the only one then discussed. Now, in collaboration with Ky Fan and K. Goldberg, the case of a circle with polar coordinates, is being investigated. One would expect to obtain the classical results that the eigenvalues are $j_{0}^{2}, r$, where the $j_{0, r}$ are the positive zeros of $J_{0}(x)$ (as a limit of the discrete results). In particular, it is of interest to see how the largest eigenvalue of the finite matrix involved approaches the 
limit. In view of the singularity of the coordinate system the proper answers to various questions about the details of discretization were doubtful. Confidence in the decisionstaken was given by experiments on SEAC, in the case of a $30 \times 30$ system. The matrix in question was a symmetric triple diagonal one of the form

$$
\left(\ldots, \sqrt{\frac{r-1}{r}}, \frac{1}{r}, \sqrt{\frac{r}{r+1}}, \ldots\right)
$$

It has been shown that

$$
\lambda_{\min } \sim \mathrm{j}_{0,1}^{2}+\mathbf{o}\left(\mathbf{n}^{-1}\right)
$$

where $\lambda_{\text {min }}$ corresponds to an nxn discretization. Further work on this problem is in progress.

J. Todd, with the assistance of Mrs. I. Rhodes and Miss J. Gager, has been making a survey of recent Russian mathematical tables. Reviews of some of these appear in Math. Reviews and in Mathematical Tables and other Aids to Computation.

Publications:

(1) Stable systems of differential equations with integrable perturbation term. H. Antosiewicz. To appear in the Journal of the London Mathematical Society.

(2) Computation of vibration modes and frequencies on SEAC. W. Cahill and S. Levy (NBS 6.4). To appear in Journal of the Institute of Aeronautical Sciences.

(3) On a problem in the theory of mechanical quadratures. P. Davis. To appear in the Pacific Journal of Mathematics.

(4) On the Lerch zeta function. F. Oberhettinger. To apper in the Pacific Journal of Mathematics.

(5) Evaluation of a definite integral. P. Henrici. An NBS report (April 1954).

(6) Asymptotic location of the zero of the Bessel polynomials. P. Henrici. In manuscript.

(7) A subroutine for computations with rational numbers. P. Henrici. To appear in the Journal of the Association for Computing Machinery.

(8) A direct approach to the problem of stability in the numerical solution of partial differential equations. J. Todd. In manuscript.

(9) Some Monte Carlo experiments for computing multiple integrals. P. Davis and P. Rabinowitz. To appear in Mathematical Tables and Other Aids to Computation.

(10) Abscissas and weights for Gaussian quadratures of high order. P. Davis and P. Rabinowitz. In manuscript.

(11) Numerical experiments in potential theory using orthonormal functions. P. Davis and P. Rabinowitz. Submit ted to a technical journal.

(12) Begrỉndung für die Beschäftigung mit numerischer analysis. J. Todd. Jahresbericht d. D.M.V. 58, 11-38 (1955).

(13) Inequalities and approximation in function spaces. P. Davis and Ky Fan. In manuscript.

(14) Matrix transformations and properties of characteristic roots. K. Goldberg. In manuscript.

(15) Note on bounds for determinants. E. V. Haynsworth. In manuscript.

(16) On asymptotic stability. H. A. Antosiewicz. In manuscript. 


\section{RESEARCH IN MATHEMATICAL TOPICS AP PLICABLE TO NUMERICAL ANALYSIS \\ Task $1101-10-5116 / 55-56$}

Origin: NBS Sponsor: Office of Naval Research

Authorized $8 / 13 / 54$

Revised $8 / 29 / 54$

Full task description: July-Sept 1954 issue, p. 5

Status: CONTINUED. The method of orthogonal harmonic functions was used to solve a boundary value problem of the first kind for an annular region bounded by two ellipses of axis ratio $2: 1$. The numerical work was carried out on SEAC using a general purpose orthonormalizing code developed by $P$. Davis and $P$. Rabinowitz. Using harmonic functions which were linear combinations of $\log z$ and the real and imaginary parts of $1, z, z^{2}, z^{-1}$, an average discrepancy of about $10^{\circ} / 0$ on the boundary was achieved. Ky Fan studied systems of inequalities concerning the absolute values of linear functionals on a complex linear space. Consistency conditions for different types of such systems (finite and infinite) of inequalities are obtained. In the case of a finite dimensional unitary space or a complex Hilbert space, a characterization of the unique solution of minimum norm by a maximum property is given. For inequalities involving completely continuous linear transformations, one of the results is the following: Let $X$ be a reflexive complex normed linear space and let $A$ be a completely continuous linear transformation from $X$ into itself. Let $y_{0} \in X, 0 \geq 0$, and let $\lambda \neq 0$ be a complex number. Then there exists an $X^{0} \in X$ satisfying $\|A x-\lambda x-y\| \leq \delta$, if and only if every solution $g \in X^{*}$ of the equation $A^{*} g=\lambda g$ satisfies the relation $\left|g\left(y_{0}\right)\right| \leq \delta\|g\|$. In the case $0=0$, this result becomes Riesz-Schauder's generalization of Fredholm's alternative theorem, except that the reflexivity of the space $X$ is required here. Results of this investigation have been written up as an additional part IV of the earlier manuscript, "On systems of linear inequalities." Ky Fan, in collaboration with I. Glicksberg (RAND Corporation) completed a paper on fully convex normed linear spaces. In collaboration with J. B. Kruskal (Princeton University), A. J. Hoffman studied the question of conditions under which polyhedra admit integral points on every face (of any dimension). Let $A$ be an integral matrix. In order that the convex set (1) $A x \geq b$ have an integral point on every face for every integral vector b such that (1) be non-empty it is necessary and sufficient that (if $k$ be the rank of A) the g.c.d. of the ( $(k)$ determinants obtainable from every set of $k$ Iinearly independent rows of A be unity.

If we pose the analogous question for (1) and for (2) $x \geq 0$, the condition becomes: every nonsingular square submatrix of $A$ is unimodular. It has been shown further that the incidence matrix for elements vs. "full" chains (chains which are not contained in other chains joining the same end points) in a partially ordered set $P$ does have this property if $P$ is the union of two disjoint sets $L$ and $U$ satisfying:

(a) no $u \in U$ precede $l \in L$,

(b) if $l \in \mathbb{L}$ immediately precedes $u \in U$, then $l$ is maximal in $L$ and $u$ is minimal in $U$,

(c) every $l \in L$ has at most one immediate successor in $L$,

(d) every $u \in U$ has at most one immediate predecessor in $U$.

T. Kato is studying the application of perturbation theory to obtain bounds for the eigenvalues of finite matrices. It is not yet clear whether the results obtained by this approach are better or worse than the classical ones.

A library of basic matrix codes is being writen. All of the 
routines accept data in a standard form. Routines which have been completed by $M$. Newman include:

MP1 General purpose input routine

M01 General purpose output routine

MS1 Computes $x$ where $A x=b, A$ an $n \times n$ matrix and $b$ an $n x 1$ vector. Here $\mathrm{n} \leq 28$. The computation time for $n=28$ is about 10 minutes.

MI1 Computes $A^{-1}$, where $A$ is an $n \times n$ matrix, and $n \leq 28$. The computation time for $n=28$ is about 15 minutes.

MM1 Computes $A B$, where $A$ is an mxn matrix, $B$ an $n x r$ matrix, and mn $\leq 400$, $\mathbf{n} \mathbf{r} \leq 400$.

MM2 Computes $A^{\prime} A$, where $A$ is an mxn matrix, and $n(m+n) \leq 840$.

MM Computes $A^{\prime} B A$, where $A$ is an mxn matrix, $B$ an mxm symmetric matrix, and $n m \leq 420, m \leq 27$.

M02 Special output routine for MM.

MA1 Computes $A \pm B$, where $A$ and $B$ are mxn matrices and $m n \leq 400$.

MF1 Computes $X$, where $X^{\prime} X=A$, $A$ an nxn symmetric positive definite matrix and $X$ an upper triangular matrix. Here $n \leq 40$.

Routines which have been completed by $K$. Goldberg include:

FS1-4 Floating subroutines for addition, multiplication, division and comparison written for conciseness and speed and without interpretive entry.

MP2 General purpose input routine which computes the norm of the data and makes it less than one if it is desirable to "unfloat" the data.

MJG1 Reduces symmetric matrix of order less than or equal to 23 to triple diagonal form by Jacobi-Givens process and stores the transformation matrix. Unfloated.

MJG2 Checks norm and "refloats" triple diagonal form. Expandable to provide absolute check on transformation of JG1.

MJG3 Computes roots and vectors of triplediagonal form by Sturm sequence. Transforms and normalizes vectors to obtain those of the original matrix.

E. Dade completed a code to find the inverse of a matrix, the elements of which are double precision floated decimal numbers, of order not exceeding 14 .

M. Newman continued his work on the coefficients Pr(n). Several new identities have been derived and some further theorems concerning these coefficients have been proved. A generalization of this problem to the coefficients of arbitrary modular forms is under way.

Publications:

(1) The normalizer of certain modular subgroups. M. Newman. To appear in the ranadian Mathematical Journal.

(2) Generalizations of identities for the coefficients of certain modular forms. M. Newman. To appear in Journal of the London Mathematical Society.

(3) Compactification of completely regular spaces. Ky Fan and F. Wagner (University of Notre Dame). In manuscript.

(4) Some inequalities concerning positive-definite Hermitian matrices. Ky Fan. Proc. Cambridge Philosophical Soc. $51,414-421$ (1955).

(5) A comparison theorem for eigenvalues of normal matrices. Ky Fan. To appear in the Pacific Journal of Mathematics.

(6) On certain series expansions involving Whittaker functions and Jacobi polynomials. P. Henrici. To appear in the Pacific Journal of Mathematics.

(7) On generating functions of the Jacobi polynomials. P. Henrici. To appear in the Pacific Journal of Mathematics. 
(8) An identity for the coefficients of certain modular forms. M. Newman. To appear in the Journal of the London Mathematical Society.

(9) Error bounds for eigenvalues of symmetric integral equations. H. Wielandt. To appear in the Proceedings of the American Mathematical Society Sixth Symposium on Applied Mathematics, held at Santa Monica, California, August 1953.

(10) Fully convex normed linear spaces. Ky Fan and I. Glicksberg (RAND Corporation). To appear in the Proceedings of the National Academy of Sciences.

(11) On eigenvalues of sums of normal matrices. H. Wielandt. Submitted to a technical journal.

(12) An inclusion theorem for modular subgroups. M. Newman. In manuscript.

(13) A theorem on alternatives for pairs of matrices. H. A. Antosiewicz. To appear in the Pacific Journal of Mathematics.

(14) On systems of distinct representatives. A. J. Hoffman and H.W. Kuhn. To appear in Annals of Mathematics Study $38^{\circ}$.

(15) Systems of linear inequalities. Ky Fan. To appear in Annals of Mathematics Study 38 .

(16) Systems of distinct representatives and linear programming. A.J.Hoffman. To appear in the American Mathematical Monthly.

(17) On a theorem of Dilworth. G. B. Dantzig (RAND Corporation) and A. J. Hoffman. To appear in Annals of Mathematics Study 38 .

(18) On "overshoot" in the "furthest hyperplane" method. R. Bryce. In manuscript.

(19) Notes on some scheduling programs. A. J. Hoffman. In manuscript.

(20) On block relaxation. L. S. Joel. In manuscript.

(21) On the minimization of concave and convex functionals. G.B.Dantzig (RAND Corporation), A.J.Hoifman, W. Hirsch (New York University). In manuscipt.

(22) How to solve a linear programming problem. A. J. Hof fman. Proceedings of the Second Symposium in Linear Programming, held jointily by the National Bureau of Standards and the U.S.A.F., January 1955, pp. $397-424$.

\section{ANALYTIC STUDY OF WAR GAMES}

Task $1101-10-5116 / 55-83$

Origin and Sponsor: Armament Branch, ARDC, USAF

Authorized $12 / 29 / 54$

Manager: H. A. Antosiewicz

Full task description: Oct-Dec 1954 issue, p. ?

Status: CONTINUED. In a recent conference initiated by the sponsor and people working under contract on similar problems, it was decided to hold a two-day symposium on topics in war games at the University of Michigan sometime in November 1955. The analytical work done up to now will be reviewed by $H$. A. Antosiewicz.

Publication:

(1) Analytic study of war games. H. A. Antosiewicz. To appear in the Naval Research Logistics Quarterly. 


\section{STUDIES IN THE THEORY OF ASYMPTOTIC EXPANSIONS}

Task $1101-10-5116 / 55-116$

Origin: NBS

Sponsor: Office of Scientific Research, ARDC, USAF

Authorized $3 / 31 / 55$

Manager: $\mathbb{P}$. Dayis

Full task description: Jan-Mar 1955 issue, p. 8

Status: CONTINUED. Necessary and suficient conditions for uniqueness classes of (Poincare) asymptotic expansions in an arbitrary domain have been obtained using the theory of conformal kernel functions. For some additional-details see Apr-June 1955 issue, p. 5.

The question of uniqueness classes has also been approached from the point of view of the theory of interpolation and approximation. Using a theorem on inequalities in Banach spaces developed by $\mathrm{P}$. Davis and Ky Fan, it has been found possible to characterize uniqueness classes by means of the completeness properties of certain sequences of analytic functions. (See also task 1101-10-1104/55-55, p.1.)

Publication:

(1) Uniqueness theory for asymptotic expansion in arbitrary domains. $P$. Davis, In manuseript.

\section{STUDY OF DIFFERENTIAL EQUATIONS FOR NERVE EXCITATION Task 1101-10-5116/56-148}

Origin and Sponsor: National Institutes of Health, Bethesda, Md.

Authorized $9 / 30 / 55$

Manager: H. A. Antosiewicz

Objective: The normal functioning of a single nerve fiber involves the development of electrical potential differences and currents along its length as well as across the membrane at its surface. The HodgkinHuxley differential equations, which are the basis of this study, express the membrane current $\mathbb{I}(t)$ in the form

$$
I(t)=r \cdot \frac{d V}{d t}+36 n^{4}(V-12)+120 m^{3} h(V+115)+\frac{3}{10}(v+10.5989)
$$

where $r$ is the membrame $c a p a c i t y, ~ V$ the difference of the membrane potential from its resting values, and $\mathbb{n}, \mathrm{m}, \mathrm{h}$ are dimensionless variables related to $\checkmark$ by the system

$$
\begin{aligned}
& \frac{d n}{d t}=a_{1}(V)(1-n)-a_{2}(V) n \\
& \frac{d m}{d t}=b_{1}(V)(1-m)-b_{2}(V) m \\
& \frac{d h}{d t}=c_{1}(V)(1-h)-c_{2}(V) h
\end{aligned}
$$

in which the coefficients are functions of $V$ only, too complicated to be stated explicitly here.

A previous investigation centered around the physiologically important "all-or-mone" phenomenon, i.e., the determination of the so-called threshold values for the current $I(t)$.

The present study will be devoted mainly to an investigation of 
the propagated action potential whose equation was given by Hodgkin-Huxley in the form

(3) $\frac{d^{2} v}{d t^{2}}=K \frac{d V}{d t}+\frac{1}{c} 36 n^{4}(v-12)+120 m^{3} h(v+115)+\frac{3}{10}(v+10.5989)$,

the subsidiary variables being defined as before. The constant $K$ depends upon the velocity of propagation and is not known in advance. One of the problems to be considered is the determination of $K$ such that the value of $V$ becomes zero when the action potential returns to zero.

Background: Previous investigations, especially of the threshold values of $I(t)$, were carried on under task 1102-20-1104/53-15 (see Oct-Dec 1952 issue, p. 34) and were continued under task 1101-10-1104/55-55 (see July-Sept $1954^{\circ}$ issue, p. 2, and Oct-Dec 1954 issue, p. 2). Both the present investigations and the earlier ones were proposed by Dr. K. Cole, presently of the National Institutes of Health.

Status: NEW. H. A. Antosiewicz has investigated the "linearized" system corresponding to equations (2) and (3) in order to obtain approximate initial values from which numerical integrations of (2) and (3) could be started. He has prepared a SEAC code for the solution of the linearized system which should prove useful in determining rough opproximation of suitable values for the parameter $\mathrm{K}$.

Publication:

(1) Automatic computation of nerve excitation. K. S. Cole (Naval Medical Research Institute), H. A. Antosiewicz and P. Rabinowitz. To appear in the Journal of the Society for Industrial and Applied Mathematics. 


\title{
2. MATHEMATICAL TABLES
}

\author{
TABLES OF $E_{1}(z), \quad(z=x+i y)$ \\ Task 1102-40-1110/43-3
}

Manager: I. Stegun

Full task description: Apr-June 1949 issue, p. 41

Authorized $7 / 1 / 47$

Status: Continued. Preparation of an introduction to accompany publication of the completed tables continued.

\section{TABLES OF COULOMB WAVE FUNCTIONS}

Task $1102-40-1110 / 47-2$

Origin: NBS

Manager: M. Abramowitz

Full task description: Apr-June 1949 issue, p. 45

Authorized $7 / 1 / 47$

Status: Continued. A new program is being prepared to obtain $G_{L}, G_{L}$, $F_{L}, F_{L}$ for given values of $\rho$ and $\eta$ and varying values of $L$. The method of computation consists of the evaluation of $G_{0}$ and $G_{0}^{\prime}$ at the turning point corresponding to the given value of $\eta$, from asymptotic expansions recently derived by C. E. Froberg (private communication), followed by analytic continuation using Taylor's formula to the desired value of $\rho$. The derivatives are obtained from recurrence relations resulting from successive differentiation of the differential equation. Values for $L>0$ are then obtained from the recurrence relations satisfied by the Coulomb functions. Spot checks made for $\eta>2$ indicate that results are correct to at least five decimal places or significant figures.

TABLES OF POWER POINTS OF ANALYSIS OF VARIANCE TESTS Task $1102-40-1110 / 51-8$

Origin: Section 11.3 , NBS

Authorized $3 / 26 / 51$

Manager: $S$. Peavy

Full task description: Apr-June 1951 issue, p. 49

Status: Continued. More runs have been made in order to expand the tables for the same values of $\alpha$ and $\beta$ (which are listed in the Jan-Mar 1953 issue, $p .48$ ). 


\section{REVISION OF MATHEMATICAL TABLES}

Task 1102-40-1110/52-7

Origin: NBS

Managers: W. F. Cahil1, I. Stegun

Authorized $8 / 10 / 51$

Full task description: July-Sept 1951 issue, p. 41

Status: CONTINUED. Revision of "Tables of natural logarithms," vol. IV, Mathematical Tables MT12 (1941), for reissue in the Applied Mathematics

Series continued.

TABLE OF ARCSIN FOR COMPLEX ARGUMENTS

\section{Task 1102-40-1110/52-14}

Origin: NBS

Manager: B. Gill

Authorized $10 / 1 / 51$

Ful1 task description: July-Sept 1951 issue, p. 41

Status: INACTIVE. For status to date, see Jan-Mar 1955 issue, p. 11.

\section{EXTENSION OF THE TABLE OF HYPERBOLIC SINES AND COSINES}

Task 1102-40-1110/52-18

Origin: NBS

Manager: K. Nelson

Authorized $9 / 17 / 51$

Full task description: July-Sept 1951 issue, p. 41

Status: CONTINUED. Proofs have been checked.

Publication: Table of hyperbolic sines and cosines ( $x=2$ to $x=10,95)$. Applied Mathematics Series 45 . In press.

TABLE OF THE MODIFIED AIRY INTEGRAL

Task $1102-40-1110 / 52-23$

Origin: NBS

Manager: P. Rabinowitz

Full task description: July-Sept 1951 issue, p. 42

Authorized $10 / 4 / 51$

Status: CONTINUED. Preparation of the manuscript for publication c ontinued.

\section{TABLE OF ERROR FUNCTION FOR COMPLEX ARGUMENTS}

Origin: NBS

Manager: W. Hall

Authorized $10 / 5 / 51$

Full task description: July-Sept 1951 issue, p. 42

Status: INACTIVE. For status to date, see Oct-Dec 1954 issue, p. 11. 


\section{EXTENSION OF TABLES OF THE EXPONENTIAL FUNCTION FOR \\ NEGATIVE ARGUMENTS \\ Task $1102-40-1110 / 52-31$}

Origin: NBS

Managers: E. Marden, $S$. Prusch

Authorized 10/9/51

Full task description: July-Sept 1951 issue, p. 43

Status: CONTINUED. Proofs have been checked.

Publication: Table of the descending exponential ( $x=2.5$ to $x=10,20 \mathrm{D})$. Applied Mathematics Series 46. In press.

\section{SPHEROIDAL WAVE FUNCTIONS}

Task 1102-40-1110/52-37

Origin: NBS

Manager: D. Liepman

Authorized 11/28/51

Full task description: Oct-Dec 1951 issue, p. 38

Status: INACTIVE.

RADIAL MATHIEU FUNCTIONS

Task 1102-40-1110/52-49

Origin: NBS

Manager: I. Rhodes

Authorized 2/1/52

Ful1 task description: Jan-Mar 1952 issue, p. 45

Status: COMPLETED.

Publication: Table of characteristic values of Mathieu's equation for large values of the parameter. G. Blanch and I. Rhodes, J. Wash. Acad. Sci. 45, 166-196 (Jume 1955); reprints available.

SIEVERT'S INTEGRAL

Task $1102-40-1110 / 52-57$

Origin: NBS

Managers: M. Paulsen, $\mathbb{P}$. O'Hara

Authorized 2/12/52

Full task description: Jan-Mar 1952 issue, p. 46

Status: INACTIVE. For status to date, see Apr-June 1955 issue, p. 9. 


\section{L-SHELL CONVERSION COEFFICIENTS}

Task 1102-40-1110/53-52

Origin: Oak Ridge National Laboratory

Authorized $5 / 20 / 53$

Manager: W. Hall

Full task description: Apr-June 1953 issue, p. 45

Status: CONTINUED. Computations for the $\mathrm{L}_{I I}$ shell have been

completed. Computations for the $L_{\text {III }}$ shell were completed for $z=25,65,75,85$;

this is approximately half of the $\mathrm{L}_{\text {III }}$ shell runs.

\section{AUTOMATIC CODING}

Task 3711-60-0009/55-65

Origin: NBS

Manager: J. Wegstein

Authorized $9 / 29 / 54$

Full task description: July-Sept 1954 issue, p. 11

Status: CONTINUED A subroutine of P. Rabinowitz for evaluating integrals of the form $\int_{a}^{B} f(x) d x$ by Gaussian quadrature, using 2-, 4-, 3-,

and 16-point formulas, was rewritten by J. Cooper for incorporation into a special copy of Base $O O$ and is being checked out. It is intended to serve as a tool for the evaluation of integrals in small problems with a minimum of coding. Entry, exit and all necessary information for using the routine will be specified by a two-word "order" or set of code words giving the integration limits, location of subroutine for $f(x)$, degree of integration formula, etc.

The possibility of generating this code to perform two-, three-, or four-fold integrations has been considered. Plans have been made to generalize the scheme to (two-fold or three-fold)integrations. Some preliminary analysis on the probable accuracy of such a systeri for two-fold integrals has been done. A report has been written describing a new threeaddress compiler code which was described in the April-June issue (see p.9). With its aid several programs have been written.

MATHEMATICAL SUBROUTINES

Task 3711-60-0009/56-160

Origin: NBS

Managers: Staff

Authorized $9 / 30 / 55$

Objective: To develop new general-purpose subroutines and service routines for addition to the SEAC library, and to assemble and record such subroutines developed in connaction with other tasks.

Background: An extensive library of often used subroutines and service routines is an essential part of the Computation Laboratory. As such new routines become available, they will be listed here for general information.

Status: NEW. A routine for solving algebraic equations was written by $U$. Hochstrasser. The procedure employs an iterative method due ta Laguerre for improving an assumed approximation to a root. Complex roots are also obtained. 
A routine for evaluating integrals by Filon's method, originally started by $P$. Rabinowitz, was completed by U. Hochstrasser. This method is useful for evaluating Fourier transforms, cf.L.N. G. Filon, Proc Roy. Soc. Ed inburgh 49, 38 (1928-1929).

formula

A routine was developed for computing $\Gamma(x)$ for real $x$ from the

$$
\Gamma(x)=\Gamma(x+n+1)[x(x+1) \cdots(x+n)]^{-1}
$$

where $\Gamma(x+n+1)$ is obtained from the asymptotic expansion (see British Association Tables, vo1. 1, Introduction) with $n=10$.

A routine was written by $\mathbb{E}$. Haynsworth for factorizing a symmetric matrix $A$ into the product $C C^{\prime}$ of a triangular matrix $C$ and its transpose. One application of this technique is the evaluation of the characteristic roots of the product of two symmetric matrices $A B$ where $A$ is positive definite. While $A B$ is in general not symmetric, CBC' is and has the same roots as $A B$, which can then be determined by means of the existing programs for symmetric matrices. Matrices up to order 28 can be factorized. 


\section{PROBABILITY OF MATHEMATICAL STATISTIC.S}

\section{BIBLIOGRAPHY AND GUIDE TO STATISTICAL LITERATURE \\ Task 1103-10-1107/49-1a}

Origin: NBS

Manager: L. S. Deming

Authorized $1 / 9 / 49$

Full task description: Apr-June 1949 issue, p. 75

Status: CONTINUED. For a description of the continuing activity on this task, see the Jan-Mar 1954 issue, p. 49.

\section{MANUAL ON FITTING STRAIGHT LINES}

Task 1103-10-1107/50-2

Origin: NBS

Manager: F. S. Acton

Authorized $3 / 1 / 50$

Full task description: Jan-Mar 1950 issue, p. 42

continued.

Status: CONTINUED. Review of the manuscript by technical advisors

TABLES TO FACILITATE DRAWING RANDOM SAMPLES

Task 1103-10-1107/51-1

Origin: NBS

Managers: C. Eisenhart, L. S. Deming

Authorized $7 / 1 / 50$

Full task description: July-Sept 1950 issue, p. 57

Status: INACTIVE. For status to date, see July-Sept 1952 issue,

\section{MISCELLANEOUS STUDIES IN PROBABILITY AND STATISTICS \\ Task 1103-10-1107/51-2}

Origin: NBS

Manager: C. Eisenhart

Authorized $7 / 1 / 50$

Full task description: July-Sept 1950 issue, p. 58

Status: CONTINUED. N. Severo prepared a manuscript on the derivation of the characteristic function of the multi-variate distribution. J. Lieblein prepared a manuscript on evaluating integrals when the parameters take on complex values.

Preliminary steps were undertaken in the development of a compilation of distribution functions and their characteristic functions, both known and new, for use in mathematical statistics. To this end two 
standard mathematical statistics texts, by M. G. Kendall and by H. Cramer, were examined, and a survey was made of the first of the Bateman volumes of integral transforms. The texts yielded about fifty entries, and the Bateman volume about two hundred.

Publications:

(1) Time-discrete stochastic processes in arbitrary sets, with applications to processes with absorbing regions and to the problem of loops in Markoff chains. D. van Dantzig. Accepted for publication (in French) in Annales de l'Institut Henri Poincaré (Paris).

(2) A comparison between the mean successive differences and the root mean square successive difference. S. Geisser. Submitted to a technical journal.

(3) A note on the normal distribution. S. Geisser. Submitted to a technical journal.

(4) Inequalities for probabilities associated with the multivariate normal distribution. I. R. Savage. Submitted to a technical journal.

PROCEDURES OF NON-PARAMETRIC STATISTICS

Task 1103-10-1107/52-2

Origin: NBS

Manager: I. R. Savage

Full task description: July-Sept 1951 issue, p. 66

Authorized $9 / 17 / 51$

Status: INACTIVE. For the latest report on this task see July-Sept 1954 issue, p. 22 .

Publications:

(1) Easily used simultaneous confidence limits for a line. W. S. Connor. Submitted to a technical journal.

(2) Contributions to the theory of rank order statistics. I. R. Savage. Submitted to a technical journal.

(3) Simultaneous tests of randomness and other hypotheses. I. R. Savage. In manuscript.

\section{STUDIES IN THE MATHEMATICS OF EXPERIMENT DESIGN} Task 1103-10-1107/53-1

Origin: NBS

Manager: W. H. Clatworthy

Authorized $10 / 15 / 52$

Full task description: Oct-Dec 1952 issue, p. 60

Status: CONTINUED. Two summer trainees, H. Pettigrew and F. L. Miller, Jr., (under the supervision of $M$. Zelen) have constructed fractional factorial designs of the $2^{\text {n }}$ series for fractions $1 / 64,1 / 128$, and $1 / 256$ and for factors up to $m=16$. This is an extension of the previous work of clatworthy, Connor, and zelen. Work is now in progress to combine the two compilations of fractional factorial designs into one large monograph suitable for publication in the NBS Applied Mathematics Series.

W. H. Clatworthy has enumerated and constructed a large number of partially balanced incomplete block (PBIB) designs thus considerably extending the list given in Bose, Clatworthy, and Shrikhande, "Tables of Partially Balanced Designs with Two Associate Classes." C. Burton and Dr. Clatworthy have worked out the duals of a number of these designs and Mr. Burton has proved some theorems regarding the existence of such 
duals. All this work on PBIB designs is being readied for publication.

Publications:

(1) Partially replicated latin squares. W. J. Youden and J. S. Hunter (American Cyanamid Co.). Accepted for publication in Biometrics.

(2) On the analysis of covariance. M. Zelen. Submitted to a technical journal.

(3) On the enumeration of partially balanced designs with two associate classes. W. H. Clatworthy. In manuscript.

(4) Exact tests of significance for combining inter-and intra-block information. M. Zelen. In manuscript.

\section{RESEARCH ON MATHEMATICAL ASPECTS OF ORDER STATISTICS ME THODS Task 1103-10-1107/55-110}

Origin: NBS

Manager: J. Lieblein

Authorized $3 / 3 / 55$

Full task description: Jan-Mar 1955 issue, p. 31

Status: CONTINUED. Correspondence was exchanged with Professor Greenberg of the University of North Carolina concerning the possibility of a monograph on the subject of order statistics, and suggestions for contents were considered. Discussion of extreme-value methods, in particular the publication below, with J. T. Hack of the U. S. Geological Survey, led to a decision to undertake application of these methods to a study of stream-bed deposits. To facilitate the understanding of extremevalue concepts, graphical aids were constructed reducing to straight lines the relationships between return period, number of years, and probability of occurrence. Advice was furnished to W. H. Sammons of the Kentucky Department of Highways regarding interpretation of rainfall records of different durations from a previously neglected aspect of extreme-value theory.

Publication:

(1) Application of extreme-value theory to cobbles and boulders in gravel deposits. W. C. Krumbein (Northwestern University) and J. Lieblein. Submitted to a technical journal. 


\section{MATHEMATICAL PHYSICS}

\section{RESEARCH IN MATHEMATICAL PHYSICS AND RELATED FIELDS Ta sk 1104-10-1115/55-57}

Origin: NBS

Manager: R.F. Dressler

Authorized $9 / 1 / 54$

Full task description: July-Sept 1954 issue, p. 27

Status: CONTINUED. P. Henrici studied the problem of numerical evaluation of

$$
f(a, b, c)=\int_{0}^{\infty} J_{\mu}(a t) J_{\nu}(b t) J_{\lambda}(c t) d t
$$

where $\operatorname{Re}(\mu+\nu+\lambda)>-1$ and $a, b, c$ are positive. This can be represented by a hypergeometric series if two of the numbers $a, b, c$ are different. Evaluation of this integral was required for an elasticity problem for the case $a=b, \mu=\nu=1, \lambda=2$.

Some theoretical aspects of Rutishauser's quotient-difference algorithm for computation of eigenvalues of a matrix were studied. This method yields non-dominant eigenvalues as well as the dominant one. Instead of the use of continued fractions as in the original method, it has now been shown that the algorithm can be related to a classical determinantal identity and to theorems in function theory.

Another study of eigenvalue computation was devoted to consideration of the effectiveness of Aitken's $0^{2}$ method applied to the vibrating membrane for an irregular L-shaped domain. Results indicated that one application is quite effective, saving about 30 percent in computing time, but repeated applications decrease the effectiveness. A three-fold application to this problem showed definite signs of instability.

In a continuation of the study concerning addition theorems for special functions, it has been shown that the classical theorems for Legendre polynomials, and Bessel and Mathieu functions, as well as the recently derived theorem for the general Legendre functions, fit into the theory relating to addition theorems for solutions of partial differential equations. Necessary conditions for their existence are (a) that the equations must possess a complete system of solutions, and (b) that the equations must admit a group of transformations.

Publications:

(1) Addition theorems for Legendre and Gegenbauer functions. P. Henrici. Accepted for publication in the Journal of Rational Mechanics and Analysis.

(2) On the vibration of a square clamped plate. M. Abramowitz and W. Cahill. J. As soc. Comp. Mach. 2, 162-168 (July 1955).

(3) Kleine Bemerkung zur asymptotischen Entwicklung des Fehlerintegrals. P. Henrici. Zeitsch, angew. Math. Phys, 6, 145-146 (1955).

(4) The representation of an integral involving Bessel functions by hypergeometric series. P. Henrici. In manuscript. 
Origin and Sponsor: Diamond Ordnance Fuze Laboratory, Department of the Army

Manager: F. Oberhettinger Full task description: July-Sept 1954 issue, p. 28
Authorized $6 / 29 / 54$ Revised $9 / 29 / 54$

Status: INACTIVE.

RESEARCH IN MATHEMATICAL ELASTICITY

Task $1104-10-5160 / 55-85$

Origin: NBS

Sponsor: Office of Scientific Research, ARDC, USAF

Manager: R. F. Dressler

Full task description: Oct-Dec 1954 issue, p. 30

Status: CONTINUED. The project to derive a practical method for analyzing all stresses and displacements in a typical corrugated diaphragm has been successfully completed this quarter, and a paper has been written by R. F. Dressler which describes in detail the methods used and the quantitative results obtained. For a capsule of Battelle shape consisting of $2 \frac{1}{2}$ corrugations and a flat central section, the tangential, normal, vertical, and horizontal displacement components have been derived, along with the normal shear stresses and the circumferential and radial stresses, for constant air pressure loading on the outer face. The separate contributions causing membrane effects and bending effects have also been obtained for the radial and circumferential stresses. Maximum stresses producing radial bending and circumferential stretching are approximately equal, although the maxima occur in different regions. The largest total stress is a circumferential tensiun, occurring on the inner face at the botton of the corrugation nearest to the edge. Its magnitude represents a stress magnification of 4130 times the loading pressure.

On SEAC using the code composed by W. Cahill, all of these quantities have been computed for two different boundary-value problems: (a) the clamped edge, and (b) the semi-free edge corresponding to applications in aneroid capsules. The centraldeflection is about six percent greater for the semi-free case than for the clamped case, both results being in very close agreement with experimental data. All other quantities are almost identical for the two cases except in a narrow region near the outer edge where very significant differences occur. Results on stresses for the semi-free case can be compared to the Grover and Bell approximate results. Good agreement occurs except near the outer boundary and in the central flat section. The computed rosults for the shear force can be compared with known exact values, obtained from static equilibrium considerations, at the five horizontal positions of the corrugations; the maximum computational error at these points is less than three percent. This order of accuracy was produced with 190 normal-size mesh intervals plus about 300 smaller intervals in the transition zones surrounding the points of discontinuous meridial curvature. Including the mid-points which must be used, this totals almost 1000 integration points over the range.

For a given diaphragm shape, the general solution by the Runge-

Kutta method applied four times on SEAC (with floating decimal point routine) required six hours total, plus another hour to form the linear combination satisfying the outer boundary conditions and to compute stresses from displacements. 
The method is equally applicable to any shapes and patterns of corrugations and is now available for practical design calculations for various shapes, thicknesses, and loading conditions. These results will be presented in a talk by $R$. F. Dressler at the national meeting of the American Society of Mechanical Engineers in Chicago, November 14-18.

For the vibrating triangular wing with two free edges, R.F.Dressler and W. Cahill have now formulated this eigenvalue problem as an order 78 unsymmetric real matrix for the cases: aspect ratio $r=2$, Poisson's ratio $\sigma=.25, .29$, and .35 . These formulations were each based upon 20 different stencil patterns defining the biharmonic operator in finite difference form, modified in various unsymmetric ways by the free edge and free corner boundary conditions. The lengthy calculations to evaluate these stencils were done by D. Liepman and A. C. Bruno. A SEAC code for the lowest eigenvalue for unsymmetric matrices up to order 96 has been programmed and written by $I$. Rhodes and U. Hochstrasser. This method computes at each step with a 19 th-degree hypergeometric polynomial function of the matrix in order to improve eigenvalue ratios to accelerate convergence. The calculation produces the bi-orthogonal families of left-hand and righthand eigenvectors. In some respects this code may be considered as one of the most complicated and difficult ones thus far successfully used on SEAC.

Results for the lowest frequency and mode obtained thus far lor the case $r=2, \sigma=.29$, are as follows: In scaled dimensionless notation the frequencies (rounded) are as follows:

$\begin{array}{ll}\text { computed from order } 28 \text { matrix } & .085 \\ \text { computed from order } 45 \text { matrix } & .079 \\ \text { computed from order } 78 \text { matrix } & .074 \\ \text { experimental result of Gustafson, et al. } & .066\end{array}$

The order 78 result is tentative since the computation bas not completely converged yet. The present value differs by 12 percent from the experimental, but the latter is too low since it contains air loading and imperfect clamping effects which might easily explain the full discrepancy. The computation requires 30 minutes per iteration and produced the .074 value after six iterations. The previous unaccelerated code required several hundred iterations for the order 45 matrix compared with 18 iterations by the new method. In spite of the unsymmetric formulation, it is seen that order 45 is clearly large enough for the first mode, but probably order 78 will be necessary for accurate determination of higher modes. I. Rhodes is now working on the code extension to obtain higher modes. Also, results for other values of $r$ and $\sigma$ have yet to be calculated.

Publication:

(1) Properties of currugated diaphragms. R. F. Dressler. In manuscript.

FOURIER TRANSFORMS OF PROBABILITY DISTRIBUTION FUNCTIONS Task $1104-10-5160 / 56-154$

Origin: NBS

Sponsor: Office of Naval Research

Authorized $9 / 30 / 55$

Managers: F. Oberhettinger, J. Lieble in

Objective: To compile a comprehensive table containing a number (about 1000) of Fourier transforms for a variety of different probability distribution functions. This will include not only the more commonly used material but also a large number of hitherto unknown results.

Background: Although the book "Tables of integral transforms," 
vol. I, by A. Erdelyi, W. Magnus, F. Oberhettinger and F. G. Tricomi, (McGraw-Hill Book Co., New York, 1954), containing a few transforms of probability functions is available, there is need for a more adequate and complete listing in a separate publication pertaining only to those functions which occur as probability distribution functions.

Status: NEW. F. Oberhettinger has generated some transforms of probability functions which were hitherto underived, and the systematic compilation is in progress. J. Lieblein is engaged on an extensive literature search for other transforms.

\section{RESEARCH IN FLUID DYNAMICS OF TWO-PHASE FLOWS} Task 1104-10-5160/56-155

Origin: Office of Naval Research

Authorized $9 / 30 / 55$

Manager: R.F. Dressler

Objective: To attempt the construction of mathematical models to isolate the basic phenomena related to the issuance of a steam jet into water, and to solve the equations governing each particular model. In particular, the problem will be considered from a one-dimensional and from a two-dimensional point of view. In the one-dimensional case, attention will first be focused on the following: (1) The derivation at a condensation interface of discontinuity conditions based upon continuity, momentum, and energy considerations, and their application to the problem of quasi-one-dimensional steady discontinuous flows of vapors in ducts and jets. (2) The study of shocks in steam, taking into account the non-polytropic variation of the thermodynamic properties of steam, and the question as to whether separate steam shocks must exist in a supersonic steam flow before a condensation interface can occur. (3) The study of the stability of such condensation interfaces. (4) The study of steam shocks and condensation interfaces considered as zones of finite width. This treatment would include an analysis from the viewpoint of kinetic theory and statistical mechanics.

Background: A better understanding of the essential physical phenomena governing condensible jet flows is desirable. Also the study of basic shock phenomena in steam has hitherto received comparatively little attention. The investigation described above is designed to combine both these objectives.

Status: NEW.

\section{RESEARCH IN MATHEMATICAL GEOPHYSICS}

Task 1104-10-5160/56-156

Origin: The American University

Authorized $9 / 30 / 55$

Sponsor: Office of Naval Research

Manager: R. Stoneley

Objective: To investigate in detail the static yielding of the earth to forces of tidal type, and also to determine the modes of oscillation and the corresponding periods for the earth using the known distributions for its density and elastic properties. 
A related problem to be investigated is the stability of gravitating elastic spheres, especially applied to the problem of the inner planets.

Background: A knowledge of the deformations is required, for instance, in order to estimate the elastic recovery of the earth after the melting of snow caps. The periods of oscillation are of particular interest in the interpretation of earth-tide observations and the longperiod oscillations shown in seismograms.

This research is being conducted by Dr. R. Stoneley of the American University, on leave from the University of Cambridge, England, with the sponsorship of the office of Naval Research. The National Bureau of standards is according guest worker status to Dr. Stoneley and is making its facilities available for the performance of this task.

Status: NEW. A monograph on elastic surface waves is in preparation by $R$. Stoneley. 


\section{MATHEMATICAL AND COMPUTATIONAL SERVICES}

1102-40-5126/50-13 RAY TRACING

Origin and Sponsor: NBS, Section 2.2

Manager: E. Marden

Full task description: Jan-Mar 1950 issue, p. 33

Status: Inactive

1102-40-5126/51-37 MOLECULAR STRUCTURE, III

Origin and Sponsor: Naval Research Laboratory, USN

Manager: P. O'Hara

Full task description: July-Sept 1951 issue, p. 50

Status: Continued. The following calculations were made for the dimethoxybenzophenone crystal: The observed intensities were corrected

for length and obliquity, resolution and polarization. After making a correction for vibrational motion the normalized structure factors

(E) were computed. The next portion of the problem involves the

determination of the sign of $E$.

\section{2-40-5126/52-44 CALCULATIONS FOR d SPACINGS}

Origin and Sponsor: NBS, Division 9

Manager: A. Futterman, R. Zucker

Full task description: Oct-Dec 1951 issue, p. 47

Status: Continued. Calculations for d-spacings were performed for the following cases: (1) tetragonal crystals: $\mathrm{Hg}(\mathrm{CN})_{2}, \mathrm{PbWO}_{4},\left(\mathrm{NH}_{4}\right)_{2}$,

$\mathrm{PdCl}_{4}, \mathrm{BaMoO}_{4}, \mathrm{CdMoO}_{4}, \mathrm{Ce}_{2}\left(\mathrm{MoO}_{4}\right)_{3}, \mathrm{BaWO}_{4}, \mathrm{SrWO}_{4} ;$ (2) hexagonal crystals:

$\mathrm{Si} \mathbf{i}_{2} \mathrm{Ta}, \mathrm{Ti}_{5} \mathrm{Si}_{3}, \mathrm{Na}_{2} \mathrm{SiF}_{6}, \mathrm{VaSi}_{2}, \mathrm{NbSi}_{2}, \mathrm{SbI}_{3} ;$ (3) orthorhombic crystals: humite, $\mathrm{TlNO}_{3}, \mathrm{MgSiO}_{3}, \mathrm{Cs}_{2} \mathrm{CrO}_{4}, \mathrm{NH}_{4} \mathrm{ClO}_{4}, \mathrm{ZrSi}_{2}, \mathrm{CaC}_{4} \mathrm{H}_{4} \mathrm{O}_{6} 4 \mathrm{H}_{2} \mathrm{O},\left(\mathrm{NH}_{4}\right)_{2} \mathrm{SO}_{4}$,

KCNS, $\mathrm{Rb}_{2} \mathrm{SO}_{4}$.

Redetermination of unit cell constants by least squares fitting to measured d-spacings was carried out for the following crystals:

(1) Tetragonal crystals: $\mathrm{BaWO}_{4}, \mathrm{SrWO}_{4}$; (2) hexagonal crystals: TaSi ${ }_{2}$, $\mathrm{Ti}_{5} \mathrm{Si}_{3}, \mathrm{SbI}_{3}, \mathrm{BiI}_{3}, \mathrm{Na}_{2} \mathrm{SiF}_{6}, \mathrm{AsI}_{3}$; (3) orthorhombic crystals: $\mathrm{NH}_{4} \mathrm{CRO}_{4}$, $\mathrm{MgSiO}_{3}, \mathrm{ZrSi}_{2}$.

\section{2-40-5126/53-27 COMPUTATION OF THERMODYNAMIC FUNCTIONS}

Oriqin and Sponsor: NBS, Section 3.2

Manager: E. Marden

Full task description: Jan-Mar 1953 issue, p. 57

Status: Continued. Calculations were performed using new physical constants for approximately 12 molecules for which thermodynamic functions have previously been computed; among them are the isotopic hydrogen cyanides and dichlorodif luorome thane. 
$1102-40-5126 / 53-51$ RADIATION DIFFUSION

Origin: NBS, Section 4.8

Sponsor: Atomic Energy Commission

Manager: J. Dogget t

Full task description: Apr-June 1953 issue, p. 57 (Neutron Diffusion III)

Status: Continued. An exact expression for the elastic scattering of electrons by nuclei was derived by N. F. Mott in 1929. Because of the complexity of the expresion, it has been evaluated for only a limited number of cases by hand computation to date. The formula involves series in Legendre (associated) polynomials, the coefficients of which depend on the Gamma functions with complex arguments. The existing tabulations of the Gamma function are not sufficiently fine in argument to avoid interpolation difficulties. So a code accurate to 8 significant figures was designed. At present the entire numerical process has been coded, and results for some light elements have been obtained.

1102-40-5126/54-13 AWARD OF PROCUREMENT CONTRACTS BY LINEAR PROGRAMMING Origin and Sponsor: New York Quartermaster Procurement Agency

Manager: H. Bremer

Full task description: Oct-Dec 1953 issue, p. 43

Status: Continued. Analysis of contract award problems continued to be processed on SEAC as submitted.

\section{1-60-0009/54-17 DEPOLYMERIZATION}

Origin: NBS, Section 7.6

Manager: J. Bram

Full t8sk description: Oct-Dec 1953 issue, p. 44

Status: Continued. A program has been prepared for the solution of the system of $N$ linear differential equations $\frac{d q}{d t}=A q$ where $A=\left\{a_{i j}\right\}$ is triangular, $q=\left\{u_{i}\right\} ; i, j=1,2, \ldots, N$. Here,

$$
\begin{aligned}
& \mathbf{a}_{\mathbf{i} i}=-(1-\sigma)(2 \mathbf{i}-1)=\lambda_{\mathbf{i}} \\
& \mathbf{a}_{\mathbf{i}, \mathbf{i}+\nu}=\mathbf{k}_{\nu}(\varepsilon, \sigma), \nu=1,2, \ldots, \mathbf{N}-1 .
\end{aligned}
$$

and $q_{i}(O)=0$ for $i<N, q_{n}(0)=1$. The program produces the required functions

$$
B(t)=\frac{2 \sum_{1}^{N}(i+1) q_{i}(t)}{\sum_{i=1}^{N} q_{i}(t)}, \quad C(t)=.1-\frac{1}{N+1} \sum_{i=1}^{N}(i+1) q_{i}(t), \quad \text { and } \quad \frac{d C}{d t},
$$

but not the functions $q_{i}$.

Defining the triangular matrix $P$ by the requirement that $q(t)=P\left\{e^{\lambda_{i} t}\right\}$, we have $P L=A P$, where $L$ is the diagonal matrix, $\mathbb{L}=\left\{\lambda_{i} \partial_{i j}\right\}$. Letting $\underline{a}$ and $\underline{b}$ denote the constant vectors

$$
\begin{aligned}
& \mathbf{a}=(1,1,1, \ldots, 1), \\
& \mathbf{b}=(2,3,4, \ldots, \mathrm{N}+1),
\end{aligned}
$$

we have

$$
\sum_{i=1}^{N}(i+1) q_{i}(t)=b P\left\{e^{\lambda_{i} t}\right\} ; \sum_{i=1}^{N} q_{i}(t)=a p\left\{e^{\lambda_{i}^{t}}\right\}
$$


The code was written to compute the vectors aP and bP; these vectors were then used in a supplementary code to get the final answers. As many as $\mathrm{N}=200$ equations can be solved with this code. The running time is one and three quarters hours. The arithmetic is done in fixed point notation, with tests (and possible descaling) at various states for overflow.

3711-60-0009/54-19 ENERGY LEVELS OF COMPLEX ATOMS

Origin: NBS, section 4.1

Manager: W. F. Cahill

Full task description: Jan-Mar 1954 issue, p. 41

Status: Completed. The energy levels of complex spectra in intermediate coupling including configuration interaction were computed for the low even configurations of the spectrum of singly ionized Tantalum (TaII).

Publication: Computation of atomic energy levels, the spectrum of singly ionized tantalum. R. E. Trees (NBS Section 4.1), W. F. Cahill, and

P. Rabinowitz. To appear in the Journal of Research of the NBS.

\section{1-60-0009/54-22 ENERGY DISTRIBUTIONS ON OPTICAL IMAGE}

Origin: NBS, Section 2.2

Manager: L. S. Joe 1

Full task description: Jan-Mar 1954 issue, p. 43

Status: Continued. Because of severe oscillations of the integrand occurring in this problem, a new code is being written utilizing Filon's method for quadrature of an oscillating function.

3711-60-0009/54-30 SPECTRUM ANALYSIS

Origin: NBS, Division 4

Manager: S. Prusch

Full task description: Jan-Mar 1954 issue, p. 46

Status: Continued. The SEAC code for searching for pairs of lines having a common difference was completed. Checking of the code is in progress.

\section{2-40-5126/54-34 EQUILIBRIUM CALCULATIONS FOR WATER}

Origin and Sponsor: Naval Ordnance Laboratory

Manager: J. Wegste in

Full task description: Apr-June 1954 issue, p. 38

Status: Terminated. No further calculations are contemplated at present. The methods developed in this task are being applied in several problems underway for the Thermodynamics Section (NBS 3.2).

\section{2-40-5126/54-35 THERMAL STRESSES IN STRUCTURES}

Oriqin and Sponsor: NBS, Section 6.4

Manager: W. Hall

Full task description: Apr-June 1954 issue, p. 38

Status: Terminated. Continued work on this task has been absorbed under task 1102-40-5126/55-123 (see p.31).

\section{1-60-0009/54-36 VELOCITY OF LIGHT}

Origin: NBS, Section 11.3

Manager: J. M. Cameron

Full task descriotion: Jan-Mar 1954 issue, p. 47

Status: Terminated. Additional third degree polynomials were fitted to data submitted by the sponsor to determine rotational constants of OCS and $\mathrm{C}_{2} \mathrm{H}_{2}$. In the future, this work will be reported under task 3737-60-0002/51-1 of the Statistical Engineering Laboratory (see p. 39). 
3711-60-0009/54-38 COMPRESSIBILITY FACTORS OF DRY AIR

Origin: NBS, Section 3.2

Manager: M. Paulsen

Full task description: Jan-Mar 1954 issue, p. 48

Status: Inactive. For status to date, see Apr-June 1955 issue, p. 12.

1102-40-5126/55-39 MOLECULAR VIBRATIONS

Origin and Sponsor: NBS, Section 3.2

Manager: K. Goldberg

Full task description: July-Sept 1954 issue, p. 16

Status: Inactive

1102-40-5126/54-43 CHARACTERISTICS OF CONDUCTING RESISTORS

ORigin and Sporsor: NBS, Section 12.1

Manager: PaGill

Full task description: Apr-June 1954 issue, p. 40

Status: Inactive. For status to date, see Apr-June 1955 issue, p. 12.

\section{1-60-0009/55-53 ELECTRONIC FUNCTIONS}

Origin: NBS, Section 4.5

Manage $r$ : W. G. Hall

Full Cas description: Apr-June 1955 issue, p. 12

Stacus: Continued. Computations have been completed, and the results were transfered to punched cards.

1102-40-5126/55-58 ELECTROMAGNETIC RADIATION FROM LIGHTNING

origin and Sponsor: NBS, Section 82.1

Manager: B. Gill

Full task description: Jan-Mar 1955 issue, p. 17

Status: Inactive. For status to date, see Jan-Mar 1955 issue, p. 17.

1102-40-5126/55-61 ELASTIC CROSS SECTION FOR NEUTRON SCATTERING

Origin and Sponsor: Naval Research Laboratory

Manager: I. Stegun

Full task description: Oct-Dec 1954 issue, p. 18

Status: Inactive. For status to date, see Apr-June 1955 issue, p. 13.

1102-40-5126/55-64 HIGI-TEMPERATURE THERMODYNAMIC TABLES (FMT)

origin and sponsor: NBS, section 3.2

Manager: J. Wegstein

Full task description: July-Sept 1954 issue, p. 18

Status: Terminated. A flow diagram has been prepared; no further work on programing or computing is contemplated at this time. The task was established originally with the intention of affording a check on parts of task 1102-40-5126/54--4, High-Temperature Properties of Water

With the completion of the latter task, the present one has lost its urgency.

\section{1-60-0009/55-66 RECONSTITUTION OF MONOCHROMATIC LIGHT INTENSITIES}

Origin: NBS, Division 30

Manager: H. Bremer

Full task description: July-Sept 1954 issue, p. 18

Status: Inactive. For status to date, see Oct-Dec 1954 issue, p. 19. 
3711-60-0009/55-68 CAYSTAL STRUCTURE CALCULATIONS

Oriqin: NBS, Division 9

Manager: A. Futterman, I. Stegun

Full task description: Jan-Mar 1955 issue, p. 18

Status: Continued. Work on this task is continuing in cooperation with

D. R. Prosen of the Mineral Products Division, who is pursuing a

National Research Council-National Bureau of Standards Research

Associateship. Dr. Prosen has developed a code for the calculation of structure factors for space groups of any symmetry, which includes anistropic or isotropic temperature factors.

\section{1-60-0009/55-69 THEORY OF DIELECTRIC RELAXATION}

\section{Origin: NBS, Section 7.6}

Manager: K. Goldberg

Eull task description: July-Sept 1954 issue, p. 19

Status: Completed. The paper explaining the method used to prove the reality of the roots of certain matrices and applying this method to the matrices arising in the theory of dielectric relaxation was completed.

Publication: Matrix transformations and properties of characteristic roots. K. Goldberg. In manuscript.

1102-40-5126/55-74 LIQUID-VAPOR TRANSITION, II

Origin and Sponsor: Naval Medical Research Institute

Manager: S. Prusch

Eull task description: Jan-Mar 1955 issue, p. 19

Status: Continued. Solution of the integral equation on punched card machines continued for two more values of the parameter and two given sets of functional values.

3711-60-0009/55-75 PARAMETER OF THE DISPERSION EQUATION FOR OPTICAL GLASS

Origin: NBS, section 1.6

Manager: R. Zucker

Full task description: Jan-Mar 1955 issue, p. 20

Status: Continued. Computations were performed to determine the refractivity of KRS -5 .

3711-60-5126/55-81 COMBINING TESTS FOR SIGNIFICANCE

Origin: NBS, section 11.3

Manager: L. S. Joel

Full task description: Oct-Dec 1954 issue, p. 23.

Status: Continued. Checking of the code continued.

\section{1-60-0009/55-82 THERMOMETER CALIBRATIONS}

origin: NBS, Section 3.1

Manager: S. Prusch

Full task description: Jan-Mar 1955 issue, p. 20

Status: Continued. Calibration tables were run on punched card machines for approximately 48 thermometers under test.

3711-60-0009/55-86 FLOW COEFFICIENTS FOR FLUIDS

Oriqin: NBS, section 6.7

Manager: P. J. Walsh

Full task description: Jan-Mar 1955 issue, p. 21

Status: Completed. Using empirical formulae similar to the following: 


$$
\begin{aligned}
& \mathbb{K}_{0}=\left(.6014-.01352 D^{-1 / 4}\right)+\left(375-.07257 D^{-1 / 4}\right)\left\{\frac{.00025}{D^{2} \beta^{2}+.0025 D}+\beta^{4}+1.5 \beta^{16}\right\}, \\
& D=.0002+\frac{.0011}{D}+\left(.0038+\frac{.0004}{D}\right)\left\{\beta^{2}+(16.5+5 D) \beta^{16}\right\},
\end{aligned}
$$

a code was written and checked to evaluate the flow coefficients $\mathbb{K}=\mathbb{K}+\mathrm{b} \lambda$ for both throat and vena-contracta taps. The range of the parameters was

$$
\begin{array}{cl}
2.067<D<15.25 & \text { (10 values) } \\
.1 & <\beta<.82 \quad \text { (42 values) } \\
0 & <\lambda<44.7214 \text { (21 values) }
\end{array}
$$

The results have been submitted to the sponsor.

1102-40-5126/55-87 "ZERO" METHOD DETERMINATION OF CRYSTAL STRUCTURE Origin and Sponsor: NBS, Section 9.7

Manager: J. Bram

Full task description: Jan-Mar 1955 issue, p. 22

Status: Inactive. For status to date, see Jan-Mar 1955 issue, p. 22 .

1102-40-5126/55-88 STRESSES IN A WALL FOUNDATION

Origin and Sponsor: NBS, Section 10.1

Managers: E. Marden, G. Hawly ins

Ful1 task description: Jan-Mar 1955 issue, p. 22

Status: Inactive. For status to date, see Apr-June 1955 issue, p. 15.

3711-60-0009/55-89 TEMPERATURE DISTRIBUTION IN SOLID WINGS HEATED

Origin: NBS, section 6.4

\section{AERODYNAMICALLY}

Manager: P. Davis, W. Cahill

FulI task description: oct-Dec 1954 issue, p. 22

Status: Terminated, in fovor of tasks of higher priority.

3711-60-0009/55-92 CYLINDRICAL ELECTRON LENS CALCULATIONS

Origin: NBS, section 4.5

Manager: W. G. Hall

Full task description: Jan-Mar 1955 issue, p. 24

Status: Completed. Four additional trajectories were computed, and the results were iransmitted to the sponsor.

1102-40-5126/55-102 COST ACCOUNTING OPERATIONS FOR HIGH SPEED COMPUTERS Oriqin and Sponsor: Bureau of Supplies and Accounts, Dept. of the Navy Managers: G. Hawkins, $E$. Marden

Full task description: Jan-Mar 1955 issue, p. 25

Status: Completed. Data for the month of April were run on UNIVAC and results were transmitted to the sponsor. A similar but new problem superseding this one has been formulated and is reported as task

$1102-40-5126 / 56-152$, p. 38 . 
1102-40-5126/55-103 MISSOURI RIVER PROBLEM

Origin and Sponsor: Missouri River Division, Corps of Engineers, U.S. Army Manager: H. Bremer

Full task description: Jan-Mar 1955 issue, p. 26

Status: Continued. The codes have been rewritten, for shorter machine time, and checked out.

1102-40-5126/55-105 AERONOMIC TIDAL WINDS OF THERMAL ORIGIN

Origin and Sponsor: NBS, Section 82.1

Managers: B. Gill, H. Howe

Full task description: Jan-Mar 1955 issue, p. 26

Status: Inactive. For status to date, see Jan-Mar 1955 issue, p. 26.

1102-40-5126/55-113 REACTOR DESIGN

Origin: Westinghouse Atomic Power Division

Sponsor: Atomic Energy Commission

Manager: U. Hochstrasser

Full task description: Jan-Mar 1955 issue, p. 28

Status: Continued. The code for finding the solution of the difference equations of the test problem mentioned in the April-June 1955 issue, p. 17, has been completed and sections of it have been checked out. In addition, several smaller codes have been written to load initial flux data, to convert and read out the final flux distribution, and to set up the iteration process of solution.

The coding of the iteration has been done in a general fashion so that comparisons between different methods of solution may be made easily and accurately. Accordingly, it is possible to "sweep" the mesh in any direction whatsoever, without changing the code, and to change the method of solving the difference equations with a minimum of coding.

\section{2-40-5126/55-115 ADSORPTION INTEGRALS}

\section{Oriqin and Sponsor: NBS, Section 3.1}

Manager: J. Cooper

Full task description: Apr-June 1955 issue, p. 17

Status: Completed. The code used to compute the integral

$$
\mathrm{T}_{0}(\nu)=\int_{\nu-\Delta \nu}^{\nu+\Delta \nu} \mathrm{y}^{-2} \sin ^{2} \mathrm{y} \exp \left(-\frac{\mathrm{s} \alpha / \pi}{x^{2}+\alpha^{2}}\right) \mathrm{d} x
$$

was modified to allow computation of the following integrals:

$$
\begin{aligned}
& \mathrm{T}_{1}(\nu)=\int_{\nu-\Delta \nu}^{\nu+\Delta \nu} \mathrm{y}^{-2} \sin ^{2} \mathrm{y} \exp \left[-\mathbf{a} \sum_{\mathbf{i}=1}^{3} \frac{\mathbf{s}_{\mathbf{i}} \alpha_{\mathbf{i}} / \pi}{\left(\mathrm{x}-\mathrm{x}_{\mathbf{i}}{ }^{2}\right)+\alpha_{\mathbf{i}}{ }^{2}}\right] \mathrm{dx} \\
& \mathbf{T}_{2}(\nu)=\int_{\nu-\Delta \nu}^{\nu+\Delta \nu} \exp \left[-22.67(\nu-\mathbf{x})^{2}-a \sum_{i=1}^{3} \frac{s_{i} \alpha_{i} / \pi}{\left(x-x_{i}\right)^{2}+\alpha_{i}^{2}}\right] d x
\end{aligned}
$$

where $s_{i}, \alpha_{i}, \Delta \nu, x_{i}$ are input parameters, and $y=(\nu-x) \pi / \Delta \nu$.

$$
\mathbf{T}_{3}(\nu)=\int_{\nu-\Delta \nu}^{\nu+\Delta \nu} \exp \left(-22.67-\mathbf{b} \frac{\left(\mathbf{x}-\mathbf{x}_{\mathbf{0}}\right)^{2}}{\alpha^{2}} \ln 2\right) \mathbf{d} \mathbf{x}
$$




$$
\begin{aligned}
& \mathbb{T}_{4}(\nu)=\int_{\nu-\Delta \nu}^{\nu+\Delta \nu} \frac{(\Delta \nu)^{2}}{(\nu-x)^{2}+(\Delta \gamma)^{2}} \exp \left(-\frac{0576}{x^{2}+.16}\right) \mathrm{d} x \\
& T_{5}(\nu)=\int_{\nu-\Delta \nu}^{\nu+\Delta \nu} \frac{(\Delta \gamma)^{2}}{(\nu-x)^{2}+(\Delta \gamma)^{2}} \exp \left(-\frac{x^{2} \ln ^{2}}{.16}\right) \mathrm{dx}
\end{aligned}
$$

where $\Delta \gamma$ and $\Delta \nu$ are input parameters.

$T_{1}(\nu)$ was evaluated for one set of input parameters for $\nu=-2.4(.04) 2.4 . T_{2}(\nu)$ was evaluated for seven sets of parameters for $\nu=-2.4(.04) 2.4 . T_{3}(\nu)$ was evaluated for nine sets of parameters for $\nu=-2.4(.04) 2.4$. $T_{4}(\nu)$ was evaluated for three sets of parameters for $\nu=-2.4(.04) 2.0(.25) 5.0 . T_{5}(\nu)$ was evaluated for one set of parameters for $\nu=0(.04) 2.0(.25) 5.0$. In addition, $T_{0}(\nu)$ was evaluated for $\nu=0(.04) 2.0(.25) 5.0$ for eight new sets of the parameters a and $\Delta \nu$ All calculations were multiplied by a normaliziog factor which was either a constant or a constant times the parameter $\Delta \nu$. The results were submitted to the sponsor and have been used by $\mathrm{H}$. J. Koskowski of the Temperature Measurements Section (3.1) in a study of slit function effects in determining infrared widths and int usities.

1102-40-5126/55-117 ATTENUATION OF PRESSURE PULSES OF FINITE AMPLITUL' Oriqin: NBS, Section 3.2

Sponsor: Bureau of Aeronautics, U. S. Navy Manager: M. Paulsen

Ful1 tosk description: Apr-June 1955 issue, p. 18

Status: Continued. Four subroutines for computing the particle velocity $\mu$ and sound velocity a at the boundaries were completed and checked out.

\section{2-40-5126/55-118 THERMOME TER CALIBRATION}

Origin and Sponsor: NBS, section 3.1

Manager: B. Gill

Eull task description: Apr-June 1955 issue, p. 18

status: Continued. It has been established that a sixth degree polynomial is satisfactory for predicting temperature-resistance differences. The code for computing calibration tables has been further refined and checked out.

\section{2-40-5126/55-121 ELECTMON. PENETRATION}

Origin: NBS, section 4.8

Sponsor: Atomic Energy Commission

Managers: P. Walsh, A. Futterman

Full task description: Apr-June 1955 issue, p. 19

status: Continued. The code which computes the electron depth distributions of elements for isotropic cases has been checked, and results for polystyrene for source energies ranging from .1 to 2.2 have been submitted to the NBS Nuclear Physics Section.

\section{2-40-5126/55-122 SOLUTION OF NORMAL EQUATIONS}

origin: Advisory Comittee on Weather Control

Sponsor: U. S. Weather Bureau

Manager: M. Newman

Full task description: Apr-June 1955 issue, p. 20

Status: Continued. Eight new runs were completed with revised data from the sponsor. 
1102-40-5126/55-123 TEMPERATURE DISTRIBUTION

Oriqin: NBS, section 6.4

Sponsor: NBS, Section 6.4

Manager: W. G. Hall

Full task description: Apr-June 1955 issue, p. 19

Status: Continued. The code was completed and checked.

1102-40-5126/55-124 EVALUATION OF INTEGRALS RELATED TO GAS FLOW

Origin: NBS, section 3.2

Sponsor: Bureau of Aeronautics, U. S. Navy

Manager: J. Cooper

Full task description: Apr-June 1955 issue, p. 20

Status: Completed. The results as reported in the previous issue, p. 20 , were transmitted to the originator.

\section{2-40-5126/55-126 AERODYNAMIC HEATING}

Origin and Sponsor: Diamond Ordnance Fuze Laboratory, Dept. of the Army Manager: B. Walter, $R$. Capuano

Objective: To solve the difference equation

$$
\Delta T_{W}=\frac{\bar{T}_{A W}^{-}-T_{W}}{\frac{1}{\bar{B}_{\mathrm{h}} \Delta t}+\frac{1}{2}}
$$

for $T_{W}$ as a function of time, where $\bar{T}_{A W}^{--}, \bar{h}_{e}$ are given functions of time and $\bar{B}$ depends on initial conditions and on $T_{W}$. Solutions are desired for different intervals $\Delta t$ and initial conditions.

Background: The unknown function $T_{w}$ represents the temperature of a thin plate moving through air. The recovery temperature $T_{A W}$ is determined from

$$
\mathbf{T}_{\mathrm{AW}}=75.0 \mathrm{~V}^{2}+\mathrm{T}_{\mathbf{0}}
$$

where $V$, the velocity, and $T_{0}$, the ambient temperature, are given functions of time. B is the reciprocal of the heat capacity per unit surface area of the plate and is given by the equation

$$
B=\frac{1}{\gamma \mathbf{c} \tau}
$$

where $\gamma=$ density, $c=$ specific heat, $\tau=$ thickness of the plate. The

function $h_{e}$, the convective heat transfer coefficient, is calculated from

$$
h_{e}=v^{0.8} h_{e_{0}}
$$

the last factor being the effective convective heat transfer coefficient at $V=1$. The symbol over $T_{A W}, B$ and $h_{e}$ indicates use of the mean of the values at the beginning and end of the time interval $\Delta t$.

Status: New. The aerodynamic heating $T_{w}$ was calculated for four missile trajectories, with each trajectory calculated for four different values of heat capacity (1/B). 
1102-40-5126/55-127 VIBRATIONS OF CIRCULAR DISC

origin and Sponsor: Evans Signal Laboratory

Manager: U. Hochstrasser

objective: To determine the solutions $\gamma$ of the equation

$$
\begin{gathered}
\left(1-\beta^{2}\right) \Gamma_{1} \Gamma_{2}+a b \Gamma_{1} \Gamma_{3}-\frac{b}{\beta}\left(3+\frac{1-v}{2} a^{2}+\frac{e}{b}-\frac{\beta^{2}}{1-v} \gamma^{2}\right) \Gamma_{1}+\frac{e a}{\beta} \Gamma_{2} \Gamma_{3} \\
-e\left(3+\frac{1-v}{2 \beta^{2}} a^{2}+\frac{b}{e}-\frac{\gamma^{2}}{1-v}\right) \Gamma_{2}-a\left(b+\frac{e}{\beta 2} \Gamma_{3}+\frac{1-\beta^{2}}{\beta}\left(4-\frac{g a^{2}}{2} \gamma^{2}\right)=0\right. \\
\text { where } \Gamma_{i}(\gamma)=\gamma \frac{J_{0}\left(C_{i} \gamma\right)}{J_{1}\left(C_{1} \gamma\right)}, i=1,2,3 ; C_{1}=1 ; C_{2}=\beta ; C_{3}=\beta \frac{2}{a(1-v)} ; \\
a=\sqrt{\frac{2\left(1+\beta^{2}\right)}{(1-v)(1+g)}} ; b=\frac{1-g \beta^{2}}{1+g} ; e=\frac{g-\beta^{2}}{1+g} ; J_{0}, J_{1} \text { are Bessel functions }
\end{gathered}
$$

of the first kind; $g, v$ are given constants; and $\beta$ is given by the relation

$$
\frac{1}{\varepsilon}=\left[1-\beta^{2} \frac{(1+q)^{2}}{g\left(1+\beta^{2}\right)^{2}}\right]^{\frac{1}{2}} \text { where } \varepsilon \text { is a parameter } 1<\varepsilon<1.1 \text {. }
$$

Also, the solutions of the corresponding equation have to be found $f:$ : the case where $\varepsilon<1$, and therefore $\beta$ is imaginary. Only those solutions are required for which

$$
0<\frac{\mathrm{d}}{\mathrm{h}}=\gamma \mathrm{a} \cdot \sqrt{\frac{1-\mathrm{v}}{6}}<200
$$

Background: The above equation is the frequency equation for the vibrations of circumferential order unity of a circular disc. $\varepsilon$ is the dimensionless resonant frequency, $d$ the diameter, and h the thickness of the disc.

Status: New. Two subroutines for computing $T_{i}$ have been written and tested on the SEAC. A code has been set up for solving the equation $2 c_{3} \gamma \Gamma_{3}=4-$ $c \frac{2}{3} \gamma^{2}$ for 30 values of $\varepsilon$.

\section{2-40-5126/55-128 GROUND REFLECTION COEFFICIENTS}

Origin and Sponsor: NBS, Section 82.1

Managers: B. Gill, H. H. Howe (82.1)

Full task description: Apr-June 1955 issue, p. 21

Status: Completed. Extensive tables of ground reflection coefficients for electromagnetic waves, totalling two hundred ten pages, have been calculated and were transmitted to the Boulder Laboratories (82.1).

\section{2-40-5126/55-129 PROCESSING OF PUBLIC HOUSING DATA}

Origin: NBS, Section 12.1

Sponsor: U. S. Public Housing Authority

Manager: I. Rhodes

Full task description: Apr-June 1955 issue, p. 20

Status: Completed. The results of trial runs have been transmitted to the sponsoring agency where they are used as a basis for decisions on future use of automatic computers. 


\section{1-60-0009/56-131 RAY TRACING}

Origin: NBS., Section 2.2

Manager: E. Marden

objective: To compute the wave front and the vignetted entrance pupil of an optical system.

Background: This is an extension of the ray-tracing computations referred to in the Jan-Mar 1950 issue, p. 33 (task 11.2/33-50-13). In that work, individual rays were arbitrarily selected and traced through the system. The principal purpose of the extension is to determine the size and shape of the vignetted entrance pupil and the wave front formed by the ensemble of such rays. A polynomial is determined which is physically interpreted as the distance between the actual wave front and the ideal reference sphere.

Status: New. The code falls naturally into three sections. A code has been written for the third part and is in the process of being debugged; it uses test data instead of calculated results from the first two parts of the code.

\section{2-40-5126/56-133 COMPLEX EIGENVALUES}

Oriqin: Moore School of Engineering

Sponsor: Office of Naval Research

Manager: I. Stegun

objective: To obtain on SEAC the largest complex eigenvalues for various order matrices.

Backqround: The problem arises in a research program conducted by the University of Pennsylvania for the Special Devices Center, U. S. Navy. The matrices are the coefficients of linearized versions of the equations of fight of a particular airplane when that plane is in certain extreme modes of flight. These modes of flight represent the worst conditions under which the plane is expected to fly, and the eigenvalues represent the "natural resonant frequencies" (both damping and oscillation) of the plane under those conditions. The stability chart criterion, developed at the Moore School of Electrical Engineering of the University of Pennsylvania, enables one to choose a numerical method and a computation interval for solving differential equations, provided one knows the largest eigenvalues of the linearized system. Thus, the computations of eigenvalues will be used to justify the choice of a particular method and interval.

Status: New. Largest complex eigenvalues have been obtained for four matrices of order 10 and two matrices of order 6 . The eigenvalues are found from the limiting form of high powers of the matrix. If $E_{\text {. }}$ represents the value of an element in some arbitrary fixed position in yur (where y is an arbitrary initial vector), then if the roots of greatest modulus are $\lambda_{1}=u+i v$ and $\lambda_{2}=u-i v$, then $\lambda_{1}$ is found by solving the equation

$$
\left(u^{2}+v^{2}\right) E_{m}-2 u E_{m+1}+E_{m+2}=0
$$

for two successive values of $m$. As a check, the equation is solved for the same m using different elements. 
1102-40-5126/56-134 TRANSMISSION-DELAY TIMES

Origin: NBS, Section 82.1

Sponsor: NBS, Section 82.1

Managers: B. Gill, H. Howe (82.1)

objective: To compute a three-argument table, showing the transmission-delay

time $a s$ a function of $n$, the number of hops; of $H$, the height of the

reflecting layer; and of $D$, the surface distance between transmitting and receiving points. Specular ray-reflection is assumed; it is also assumed that the speed of the wave is constant throughout its path and that the earth is spherical. Two other tables are also to be computed,-one showing $\varnothing_{0}$, the angle between the ray and the vertical at the point of reflection; and one showing $\beta$, the angle between the ray and the horizontal at point of transmission or reception. The formulas involved are:

$$
\begin{aligned}
\text { Delay time }= & (2 \mathrm{n} / \mathrm{c})\left[\sqrt{2}(\text { vers } \mathrm{y})(1+Q)+Q^{2}-\mathrm{y}\right] \\
\emptyset_{0} & =\tan ^{-1} \frac{\sin \mathrm{y}}{\operatorname{vers} \mathrm{y}+Q} \\
\beta & =\frac{1}{2} \pi-\varnothing_{0}-\mathrm{y}
\end{aligned}
$$

where

$$
\mathbf{y}=\mathbf{D} / 2 \mathbf{n R}, \quad \mathbf{Q}=\mathbf{H} / \mathbf{R} \text {. }
$$

Here $R$ is the radius of the earth, and $c$ is the speed of light.

Background: If a short pulse of electromanetic energy is transmitted, it may sometimes be received at a distant station by reflection from the ionosphere one or more times, or by a ground wave traveling around the surface of the earth. The sky wave will arrive later than the ground wave by an amount called the transmission-delay time. If certain assumptions are made, the transmission-delay time can be computed, or, conversely,

an observed time can be used to check assumptions about the transmission. Status: New.

\section{2-40-5126/56-136 CALCULATION OF WAVE FUNCTIONS BY HARTREE METHOD}

\section{Origin: Naval Research Laboratory}

Manaqer: S. Peavy

Objective: To solve the Schroedinger equation

$$
\begin{aligned}
& \frac{1}{\mathbf{r}^{2}} \frac{\mathrm{d}}{\mathrm{d} \mathbf{r}}\left(\mathbf{r}^{2} \frac{\mathrm{d}}{\mathrm{d} \mathbf{r}} \psi\right)+\frac{2 \mathrm{~m}}{\mathbf{h}^{2}}[\mathbf{E}-\mathbf{v}(\mathbf{r})] \psi=0 \\
& V(r)=\frac{3}{2} \cdot \frac{g^{2}}{\mu r} \int_{0}^{\infty}|\psi(z)|^{2}\left(e^{-\mu(r+z)}-e^{-\mu}|r-z|\right) z d z .
\end{aligned}
$$

The problem can be simplified by the substitution $\psi=R / r$. The only desired solutions are those for which $\mathrm{lim} R / \mathrm{r}=0$.

Background: The problem arises from an $\overrightarrow{a t} \overrightarrow{t e m p t}$ to calculate the best oneparticle wave function for various nuclei. It was proposed by $R$. Jastrow and J. Aviles of N.R.L.

Status: New. The code is completed and checked out. 
1102-40-5126/56-137 STABILITY OF SUPPORTED PLATES

Origin and Sponsor: National Advisory Committee on Aeronautics Manager: R. Zucker

objective: To evaluate the stiffness parameter $\psi_{1} b^{3} / \pi^{4}$ D by solving for $z$ in the equation

$$
\begin{aligned}
& \sum\left(\frac{A_{n}^{2} S_{n}}{d}-1\right) \sum \frac{A_{n} S_{n}}{d} \quad \sum \frac{A_{n} U_{n} x}{d} \quad \sum \frac{A_{n} S_{n} y}{d} \\
& \sum \frac{A_{n} s_{n}}{d} \quad \sum \frac{s_{n}}{d} \quad \sum \frac{u_{n} x}{d} \quad \sum \frac{s_{n} y}{d} \\
& \sum \frac{A_{n} U_{n} x}{d} \quad \sum \frac{u_{n} x}{d} \quad \sum\left(\frac{S_{n} x^{2}}{d}+z\right) \quad \sum \frac{U_{n} x y}{d} \\
& \sum \frac{A_{n} s_{n} y}{d} \quad \sum \frac{s_{n} y}{d} \quad \sum \frac{u_{n} x y}{d} \quad \sum\left(\frac{s_{n} y^{2}}{d}+z\right) \\
& \text { where } A_{n}=1+\left(\frac{\beta_{n}}{r}\right)^{2}, \quad z=\frac{r}{2} \cdot \frac{\pi^{4} D}{\left(\psi_{1}+\psi_{2}\right) b^{3} \cdot \beta^{4}} \text {, } \\
& s_{n}=A_{n}{ }^{2}-k_{c} \beta^{2} \quad d=s_{n}{ }^{2}-U_{n}{ }^{2} \\
& u_{n}=\frac{2}{r} k_{s} \beta^{3} n \quad x=\sin \frac{n \pi}{r} \\
& \sum=\sum_{n=1,3,5, \ldots . \quad y=\cos \frac{n \pi}{r}}^{\infty}
\end{aligned}
$$

Values are required for various given combinations of $k_{c}, k_{s}, \beta$, and $r=2,3$. When $r=2, \psi_{2}=0$, and only the first three rows and columns of the determinants are used; when $r=3, \psi_{1}=\psi_{2}$ and the entire determinant is used.

Background: The computations arise in connection with the stability analysis of supported plates under direct compression and shear loads. $\psi, b 3 / \pi \mathrm{D}$ is a non-dimensional deflection restraint parameter. For the theory, see NACA Technical Note 2987, "Charts Relating the Compressive Buckling Stress of Longitudinal Supported Plates to the Effective Deflectional and Rotational Stiffness of the Supports," by R. A. Andorson and J. W. Semorian.

Status: New. Computations for the case $r=3$ were completed; those for $r=2$ are in progress.

\section{2-40-5126/56-138 CAYSTAL COUNTER EFFICIENCY}

\section{Origin and Sponsor: Naval Research Laboratory}

\section{Manager: L. Joel}

Objective: Given a cylindrical sodium-iodide counter of radius $R$ and length b

placed on the polar axis of the coordinate system $(r, \theta, \varnothing)$, with an isotropic $\gamma$ source $S$ placed at the origin, a distance a from the near end of the counter. To compute the counter efficiency $\varepsilon$ for every combination of 18 crystal sizes; 21 values of $\sigma$, the gamma absorption cross section in $\mathrm{cm}^{2} / \mathrm{g}$, and for 12 distances a:

$$
\begin{gathered}
\mathcal{E}=\left(1-\cos \theta_{1}\right)^{-1}\left\{1-\cos \theta_{1}-\int_{0}^{\theta_{2}} \sin \theta \mathrm{e}^{-M \sigma b \sec \theta} \mathrm{d} \theta\right. \\
\left.-\int_{\theta_{2}}^{\theta_{1}} \sin \theta \mathrm{e}^{-M \sigma(R \csc \theta-a \sec \theta)} \mathrm{d} \theta\right\}
\end{gathered}
$$


where $\theta_{1}=\tan ^{-1} \frac{\mathbb{R}}{a}, \quad \theta_{2}=\tan ^{-1} \frac{\mathbb{R}}{a+b}$,

$M$ is the crystal density in $\mathrm{g} / \mathrm{cm}^{3}=3.66$.

Background: These computations are being made in connection with a study to obtain more reliable standards needed in the evaluation of crystals as radiation counters. The problem was suggested by $R$. Jastrow, F. Brooks, and A. Wolicki of the NRL.

Status: Completed (New). The problem was coded and the computations were capried our-yielding toral of 4536 values. The results have been transmitted to the sponsor.

\section{2-40-5126/56-139 STUDY OF INTERNUCLEAR POTENTIAL FOR $\mathrm{H}_{3}$}

Origin and Sponsor: NBS, Section 3.2

Manager: E. Heynsworth

objective: To find solutions $\mathbb{C}_{i}$ and $\varepsilon_{j}$ of the simultaneous secular equations

$$
\left.\begin{array}{l}
\left(H+G^{\alpha}\right) C_{1}^{\alpha}=\varepsilon_{1}^{\alpha} s C_{1}^{\alpha} \\
\left(H+G^{\beta}\right) C_{1}^{\beta}=\varepsilon_{1}^{\beta} s C_{1}^{\beta} \\
\left(H+G^{\alpha}\right) C_{2}^{\alpha}=\varepsilon_{2}^{\alpha} s c_{2}^{\alpha}
\end{array}\right\}
$$

where $H$ and $S$ are given $3 \times 3$ symmetric matrices, $G^{\alpha}$ and $G^{\beta}$ are $3 \times 3$ symmetric matrices whose elements are functions of the vector components $\mathrm{C}_{i}^{\alpha}$ and $\mathrm{C}_{i}^{\beta}$. These vector components obey two scaling equations and in addition, the equation:

$$
\begin{gathered}
c_{11} c_{12}+s_{a b}\left(c_{11} c_{22}+c_{21} c_{12}\right)+c_{21} c_{22}+s_{b c}\left(c_{31} c_{22}+c_{21} c_{32}\right) \\
+c_{31} c_{32}+s_{a c}\left(c_{31} c_{12}+c_{11} c_{32}\right)=0
\end{gathered}
$$

Trial vectors $C_{1}^{\alpha}, c_{1}^{\beta}$ and $c_{2}^{\alpha}$ which are properly scaled and obey equations (2) are assumed, and from these the $G^{\alpha}$ and $G^{\beta}$ matrices are calculated and the secular equations ( 1 ) are solved. This gives new vectors $C$, and the process is repeated until the vector components assumed are equal to the vector components obtained.

Background: The equations arise from a project involving the study of the binding energy; the internuclear potential of the $\mathrm{H}_{3}$ system is obtained as

- Punction of internuclear distance and angle by the molecular orbital selfconsistem lield approximation. The activation energies of the exchange reactions involving atomic and molecular mydrogen and its isotopes will then be computed. A more realistic interauclear potential function for the calculation of the second virial coefficients and transport coefficients of hydrogen and its isotopes mey result from the calculations.

We consider the interaction of three hydrogen atoms separated by the distances $\mathbb{R}, \mathbb{R}^{\prime}$ where $(1) \mathbb{R}^{\prime} \mathbb{R}^{\prime}$ or $(2) \mathbb{R}=\mathbb{R}$ ? We want to calculate the binding energy of the eriatomic hydrogen system. To do this we assume that the ground state energy of the system is given by the schroedinger wave equation, $H=E \psi$, where $H$ is the Hamiltomin operator of the system, $\psi$ is the wave functions describing the system and $E$ is the energy corresponding to W. We assume that $\psi$ is formed as the antisymmetrized product of molecular spin orbitals: 


$$
\psi=\frac{1}{\sqrt{3 !}}\left|\begin{array}{lll}
\psi_{1}^{1} & \psi_{2}^{1} & \psi_{3}^{1} \\
\psi_{1}^{2} & \psi_{2}^{2} & \psi_{3}^{2} \\
\psi_{1}^{3} & \psi_{2}^{3} & \psi_{3}^{3}
\end{array}\right|
$$

where $\psi_{1}=\varnothing_{1}(\alpha), \Downarrow_{2}=\varnothing_{1}(\beta) ; \quad \Downarrow_{3}=\emptyset_{2}(\alpha)$;

$\alpha$ and $\beta$ are orthonormal spin functions,

$$
\varnothing_{i}=\sum_{j} c_{j i} x_{j}
$$

and the $\mathrm{J} \cdot \mathrm{s}$ range over all atomic orbitals. The $\chi_{i}$ are 15 atomic functions on the hydrogen at oms $a, b$ and $c$, and the $\emptyset_{i}$ are linear combinations of these functions forming orthonormal sets of molecular orbitals.

$$
\begin{aligned}
& \mathbf{H}=\sum_{\mathbf{u}} \mathbf{H}^{\mathbf{u}}+\frac{1}{2} \sum_{\mathbf{u} \neq \nu} \frac{1}{\mathbf{r}_{\mathbf{u} \nu}}+\mathbf{V}(\boldsymbol{R}), \\
& \mathbf{H}^{\mathbf{u}}=-\frac{1}{2} \nabla_{\mathbf{u}}^{2}-\sum_{\mathbf{p}} \frac{1}{\mathbf{r}_{\mathrm{pu}}}, \text { p ranges over all nuclei. }
\end{aligned}
$$

On substitution of $\Psi$ into the Schroedinger wave equation and by taking advantage of the orthonormality properties of the $\varnothing_{i}$ and $X^{\prime} s$, the energy of the system is found to be

$$
\begin{aligned}
& \mathbf{E}=\int \psi * H \psi d \tau \\
& \mathbf{E}=\sum_{\mathbf{i}}^{\alpha+\beta} \mathbf{H}_{\mathbf{i}}+\frac{1}{2} \sum_{\mathbf{i}, \mathbf{j}}^{\alpha+\beta} \mathrm{J}_{\mathbf{i} \mathbf{j}}-\frac{1}{2}\left(\sum_{\mathbf{i}, \mathbf{j}}^{\alpha}+\sum_{\mathbf{i}, \mathbf{j}}^{\beta}\right) \mathrm{K}_{\mathbf{i} \mathbf{j}}
\end{aligned}
$$

where $\sum^{\alpha+\beta}$ means sumnation over molecular orbitals associated with spin functions $\alpha$ and $i_{\beta}$, where $H_{i}, J_{i}$ and $K_{i}$ are functions of the coefficients, and where * denotes the conjugate transpose. The energy corresponding to the ground state is obtained by varying the parameters of $E$ to obtain minimum energy. This corresponds to solving equation (1) for molecular coefficients until self-consistency is obtained. The $H_{i}, J_{i}$ and $K_{i}$ are then calculated and $E$ is
found.

References: (1) R. S. Mulliken, ONR Report 1947, University of Chicago. (2) C. C. J. Roothaan, Modern developments in MO theory, Rev. Modern Physics 23,69 (1951). (3) V. Grifling et al J. Chem. Phys. 23 , (1955). (4) G.Berthier, J. Chem. Phys. (July-August 1954). (5) Pople and Nesbitt, J. Chem. Phys. 22, (Letter to Editor) 1954.

The problem was proposed and formulated by Dr. B. Ransil, who is pursuing a National Regearch Council-National Bureau of Standards Postdoctoral Research Associateship in the NBS Thermodynamics Section (3.2).

Status: New. Preliminary matrix subroutines have been coded and checked out. Coding of the overall problem is in progress. 
1102-40-5126/56-152 COST ACCOUNTING OPERATIONS FOR HIGH SPEED COMPUTERS, II Origin and Sponsor: Bureau of Supplies and Accounts, Department of the Navy Manager: G. Hawkins

objective: To program cost accounting operations of the originating agency

for performance on electronic computers; in particular, to distribute monthly expenditures, unliquidated obligations, man hours, and work measurement data to categorized accounts and suballotment functions; to compute cost of labor per man hour; to determine, of the total Naval Industrial Funds, the amount of such funds to be paid by the Bureau of Supplies and Accounts, using as a basis for the computations certain supplementary data reported by shipyard installations; to audit incorrect expenditure accounts; and to compute quarterly summary reports.

Background: This problem is an outgrowth of task 1102-40-5126/55-102 (see Jan-Mar 1955 issue, p. 25). After evaluating the information obtained from the afore mentioned task, it was decided to increase both the number of the different types of input data and the resultant output, much of which could be secured through the accumulation of by-products.

The Bureau of Supplies and Accounts of the Nayy Department in Washington received monthly recapitulations of financial obligations and expenditures for supply operations from more than $60 \mathrm{U}$. S. Naval supply depots, U. S. Naval supply centers, U. S. Naval shipyards, U. S. Naval stations, $U$. S. Naval submarine bases, $U$. S. Naval fuel depots, construction battalions, and other supply activities. There is also reported the number of man hours employed and work measurement units produced at these activities. These data are used for the administration of current funds and as a bas for projecting budget requests for future requirements. Status: New. Coding the problem for UNIVAC is in progress. 


\section{STATISTICAL ENGINEERING SERVICES}

\section{COLLABORATION ON STATISTICAL ASPECTS OF NBS RESEARCH AND TESTING \\ Task 3737-60-0002/51-1}

Origin: NBS

Managers: W. J. Youden, J. Cameron

Authorized $7 / 1 / 50$

Full task description: July-Sept 1950 issue, p. 60

Status: CONTINUED. The following are representative examples of statistical assistance and advice provided by members of the Statistical Engineering Laboratory to a number of Bureau personnel during this quarter:

(1) Fitting of polynomials to atomic spectra data, using SEAC, for E. K. Plyler and H. C.Allen, Jr., of Section 4.2.

(2) Analysis of data to determine effects of size and shape on noise of composition type resistors, for G. T. Conrad, Ir., of Section 1.6 .

(3) Least squares determination of constants of the curve relating velocity of sound in water with temperature, and statistical analysis to determine error of measurement process and appropriate degree of a polynomial, using SEAC, for M. Greegspan of Section 6.1.

(4) Multiple regression analysis of data on amplifier circuits, for J.H. Muncy, of Section 6.1 .

(5) Design of experiment for intercomparing standards of luminosity, for Teele, of Section 2.1 .

(6) An experimental plan was devised for the testing of a new device by personnel in DOFL. This plan involved seven factors at varying levels totaling 5184 different combinations. The final experimental plan required only one-fourth of these combinations. (This work was ferformed on a reimbursable basis.)

(7) An analysis was carried out for J. Richmond of Section 9.4, to determine how well experienced judges agree among themselves as compared to a group of inexperienced judges with respect to qualitativi ratings of color samples.

(8) An experinent was planned to evaluate the effects of various temperatures on Younç's Modulus, for J. B. Wachtmar of Section 9.1 .

Publications:

(1) Variability of wool contenc in part wool blankets. E. Horowitz (7.5) and W. S. Connor. ASTM Bulletin 208, 42-45 (Sept. 1955).

(2) More scientists. W. Jouden. Submitted to a technical journal.

(3) National physical standards and design of experiments. W. J. Youden. Submitted to a technical journal.

(4) A simplified calibration of platinum versus platinum-rhodium thermocouples. B.E.Squires (3.1) and M. Zelen. In manuscript.

STATISTICAL SERVICES FOR COMMITEE ON SHIP STEEL, NRC Task $1103-40-5105 / 52-1$

Origin and Sponsor: Ship Structure Committee, NRC Authorized $12 / 1 / 51$

Manager: W. J. Youden

Full task description: Oct-Dec 1951 issue, p. 58

Status: CONTINUED. A multiple regression study of the effect of chemical composition on ship steel was begun. 
RESEARCH IN APPLICATIONS OF MATHEMATICAL STATISTICS TO PROBLEMS OF THE CHEMICAL COHPS

Task $1103-40-5118 / 52-1$

Origin and Sponsor: Biological Laboratories,

Chemical Corps, Dept. of the Army

Authorized $10 / 1 / 51$

Manager: C. Eisenhart

Ful1 task description: Oct-Dec 1951 issue, p. 57

Status: CONTINUED. The catalogue of fractional replicated designs of the $2^{\text {n }}$ series has been extended to $n=13,14,15,16$ factors, and to fractional replicates of $1 / 64,1 / 128,1 / 256$ of a full factorial. These results are being combined with previous results for publication.

A code for computing

$$
U(\alpha, \beta, h)=\sum_{d=1}^{\infty} \frac{e^{-h_{h} d}}{d !} \int_{-\infty}^{\alpha+\beta \log d} \frac{e^{-\frac{1}{2} t^{2}}}{\sqrt{2 \pi}} d t
$$

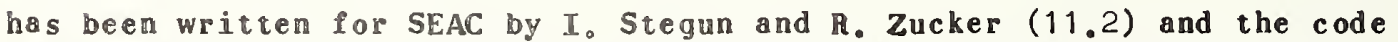
was checked. A note describing the fitness of the code is being written. The usual formulas for computing $p\{T>T\}$, where $T$ is an observed value of some statistic such as $t, F, x^{2}, 8 t c$. , are $n 8 t$ in the best form for computation. Some work has been done on seeking an alternate formula for the mechanizotion of such computations.

\section{STATISTICAL ANALYSIS AND DESIGN OF EXPERIMENTS}

FOR THE U. S. GEOLOGICAL SURVEY

Task $1103-40-5140 / 54-1$ Origin and Sponsor: U. S. Geological Survey,

Authorized $10 / 9 / 53$

Managers: C. Eisenhart, W. J. Youden

Full task description: Oct-Dec 1953 issue, p. 50

Status: CONTINUED. (1) Statistical studies we re continued on the sampling of fine-grained deposits in streams for use in a study of mineral content for Dorothy Carroli of the Sedimentary Petrology Project of the Geochemistry and Petrology Branch. (2) Some work was done on the statistical aspects of the problem of splitting samples of crushed rock for F.J. Flanagan.

MANUAL ON EXPERIMENTAL STATISTICS

FOR ORDNANCE ENGINEERS

Task 1103-40-5146/55-93

Origin and Sponsor: Office of Ordnance Research Manager: Co Eisenhart

Full task description: Oct-Dec i954 issue, p. 28

Status: CONTINUED. Further conferences at Ordnance establishments were held to determine the kind of manual which would be most useful to Ordnance Engineers and to discuss the type of statistical problems that occur. A tentative outline of the manual has been prepared and drafts have been made of some sections. 


\section{AP PLICATION}

of

\section{NATIONAL BUREAU OF STANDARDS AUTOMATIC COMPUTER (SEAC)}

The record of SEAC operations for tasks of the Applied Mathematics Division for the period July 1 through September 30 is as follows:

Task No.

\section{NBS:}

$1104 / 55-55$

$5116 / 55-56$

$5116 / 56-148$

$1110 / 47-2$

$1110 / 55-94$

$5126 / 51-8$

$5126 / 52-44$

$5126 / 53-25$

$5126 / 53-27$

$5126 / 53-29$

$5126 / 53-48$

$5126 / 53-51$

$0009 / 54-15$

$0009 / 54-17$

$0009 / 54-19$

$0009 / 55-53$

$0009 / 55-65$

$5126 / 55-68$

$5126 / 55-81$

$5126 / 55-82$

$0009 / 55-86$

$5126 / 55-87$

5126/55-92 5126/55-97

0009/55-99

$5126 / 55-115$

5126/55-117

$0009 / 55-118$

$5126 / 55-121$

$5126 / 55-126$

$5126 / 56-128$

$5126 / 56-129$

$5126 / 56-134$

5126/56-135

$5126 / 56-139$

$5126 / 56-141$

$5126 / 56-145$

$0002 / 52-1$

\section{Title}

Research in numerical analysis

Research in mathematical topics applicable to numerical analysis

Nerve fiber reaction

Tables of Coulomb wave functions

Tide tables

Tables of power points of analysis of variance tests

Calculations for d-spacings

Legendre function

Thermodynamics functions

Dynamic behavior of aircraft structure

Analysis of ionospheric data

Radiation diffusion

Matrix reduction

Depolymerization

Energy levels of complex atoms

Electronic functions

Automatic coding

Crystal structure calculations

Combining tests for significance

Thermometer calibrations

Flow coefficients for fluids

"Zero" method determination of crystal structures

Cylindrical electron lens calculations

High temperature properties of air

Inteqrals of products of Bessel functions

Adsorption integrals

Attenuation of pressure pulses of finite amplitude

Thermometer calibrations

Electron penetration

Aerodynamic heating

Ground reflection coefficients

Processing of Public Housing data

Transmission delay times

Evans hyperbolic charts

Study of internuclear potential for $\mathrm{H}_{3}$

Spectro calibration

Gamma-ray spectroscopy

Statistical aspects of NBS administrative operations

Hours Used:

Code Productive

Checking operations

8

4

1

16

9

1

1

5

19

14

2

1

9

2

13

59

1

31

2

9

4

2

3741

3

1

3

24

1

$\frac{3}{6}$

33

5

8

5
3

.

$\frac{1}{9}$

7

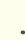

4
9
1
3
6
3
2
5
3
8
5
3


Hours Used:

Task No.

\section{Tit le}

NBS:

$5160 / 55-85$

Misc.

II

II

II

II

Other:

1110/53-52

$5126 / 51-3$

$5126 / 53-45$
$5126 / 54-13$

$5126 / 54-44$

5126/55-61

$5126 / 55-104$

$5126 / 55-113$

$5126 / 55-119$

$5126 / 55-122$

$5126 / 55-125$

$5126 / 55-127$

$5126 / 56-130$

$5126 / 56-133$

$5126 / 56-136$

$5126 / 55-137$

$5126 / 56-138$

$5126 / 56-142$
Research in mathematical elasticity

Least squares

Determinants

Matrix factoring, subroutines, etc.

Lomme 1 function

Roots of polynomials

L-She 11 conversion coefficients

Equations of heat transfer type

Applications of game theory

Award of procurement contracts for linear programming

Flight performance computations

Elastic cross section for neutron scattering

Fuse problem

Reactor design

Field rocket problem

Solution of normal equation

Matrix multiplication

Vibrations of circular disc

Aircraft responses

Complex eigenvalues

calculation of wave functions

Stability of supported plates

Crystal counter efficiency

Matrix problem c.ode

checking

Productive

12

12
4

Operations

109

1

2

1

3

2

4

76

1

20

4

2

20

14

10

3
10

34

21

2
10

4

Totals: $\frac{1}{288}$

667 


\section{Lectures and Symposia}

Note: In general, copies of papers or talks listed in this section are not available from the National Bureau of standards. If and when a paper is to be published, it will be listed in the section of this report on Publication Activities.

\section{Statistical Engineering Laboratory Seminar}

HAMMESLEY, J. M. (University of oxford) Antithetic variate method in Monte Carlo computations. September 16.

\section{Papers and Invited Talks Presented by Members of this saff at Meetings of outside Organizations}

Papers presented at the meeting of the Association for Computing Machinery, Philadelphia, Pa., September 14-16:

TODD, J., and P. DAVIS. Conformal mapping.

WEGSTEIN, J. Accelerating convergence of iterative processes.

Talks presented at the Summer Seminar and rolloquium Series on Numerical Analysis of the Numerical Analysis Research Group, University of ralifornia at Los Angeles:

HENRICI, P. Evaluation of some definite integrals on SEAC: I, July 15; II, July 19. The quotient-difference algorithm of H. Rutishauser: I, July 20; II, July 21 .

TAUSSKY-TODD, 0. Integral group matrices. June 27.

TODD, J. Topics in numerical analysis. A series of three lectures. July $5,6,7$.

rLATWORTHY, W. Incomplete block designs. Presented at the Department of Agriculture, Washington, D. C., September 16.

DAVIS, P. On the analytic continuation of mapping functions. Presented before the meeting of the American Mathematical Society, Ann Arbor, Michigan, August 30-September 3. 
HENRICI, P. Addition theorems for solutions of partial differential equations. Presented at the Seminar for Applied Mathematics and Statistics, Stanford University, California, August 13. Automatic computations with power series. Presented before the meeting of the Association for Computing Machinery, Philadelphia, Pa., September $13-14$.

HOFFMAN, A. and H. W. KUHN (Bryn Mawr College). Systems of distinct representatives and other combinatorial applications of linear programming. Presented at the meeting of the Institute of Mathematical statistics, Ann Arbor, Michigan, August 29.

YOUDEN, W. J。 National physical standards and design of experiments. Presented before the 29 th Session of the International statistical Institute, Rio de Janeiro, Brazil, June 30. Design of experiments in the physical sciences. Presented at a Biometric Meeting, Pampinas, Brazil, July 5. August 3 . Dice, data, and deductions. Talk given to NBS summer trainees, Making good measurements. Presented before the Gordon Research Conference of the AAAS, Meriden, New Hampshire, August 8 . What is a statistician? Presented before the Lions r.lub, Washington, D. C., August 25. Making good" measurements. Presented at the Naval Gun Factory, Washington, D. C., August 30 . Design of experiments in the physical sciences. Presented at the Naval Gun Factory, Washington, D. C., September ${ }^{\text {. }}$ 


\section{Publication Activities}

\section{PUBLICATIONS THAT APPEARED DURING THE QUARTER}

\subsection{Technical Papers}

(1) On the vibration of a square clamped plate. M. Abramowitz and W. F. Cahill. J. Assoc. Comp. Mach. 2, 162-168 (July 1955).

(2) On the design of two-dimensional nozzles by the method of characteristics. B. Chaix (Federal Institute of Technology, Zurich) and P. Henrici. J.Aeronaut. Sci。22, 140-142 (1955).

(3) Some inequalities concerning positive-definite Hermitian matrices. K. Fan. Froc. Cambridge Philosophical Soc. 51, 414-421 (1955).

(4) How to solve a linear programming problem. A. J. Hoffman. Proceedings of the Second Symposium in Linear Programming, held jointly by the National Bureau of Standards and the U.S.A.F., Washington, D. C., January 1955, pp. 397-424.

(5) Variability of wool content in part wool blankets. E. Horowitz (NBS Section 7.5) and W. S. Connor. ASTM Bulletin 208, 42-45 (sept.1955).

(6) Begründung für die Beschäftigung mit numerischer Analysis. J. Todd. Jahresbericht d. Deutschen Mathematiker-Vereinigung 58, 11-38(1955). (Translation of "Motivation for working in numerical analysis.")

(7) Discrete approximations to elliptic differential equations. W. Wasow. Zeit. angew. Math. Phys . 6, 81-97 (1955).

1.5 Miscellaneous

(1) Proceedings of the Second Symposium in Linear Programming, held jointly by the National Bureau of Standards and the United States Air Force, January 1955.

2. MANUSCRIPTS IN THE PROCESS OF PUBLICATION SEPTEMBER 30, 1955

2.1 Mathematical Tables

(1) Table of hyperbolic sines and cosines, $x=2$ to $x=10$, 9S. Applied Mathematics Series 45. In press, U. S. Government Printing office.

(2) Table of the descending exponential, $x=2.5$ to $x=10$. Applied Mathematics Series 46. In press, U. S. Government Printing office.

\subsection{Technical Papers}

(1) A theorem on alternatives for pairs of matrices. H. Antosiewicz. Accepted, Racific Journal of Mathematics.

(2) Analytic study of war games. H. Antosiewicz. Accepted, Naval Research Logistics Quarterly. 
(3) Asymptotic solution of linear differential equations with a parameter. H. Antosiewicz. Submitted to a technical journal.

(4) On a certain integral involving Bessel functions. H. Antosiewicz. Submitted to a technical journal.

(5) On the differential equation $\ddot{x}+k(f(x)+g(x) \dot{x}) \dot{x}=k e(t)$. H. A. Antosiewicz. Submitted to a technical journal.

(6) Stable systems of differential equations with integrable forcing term. H. A. Antosiewicz. Accepted, Journal of the London Mathematical. Society.

(7) Computation of vibration modes and frequencies on SEAC. W. F. Cahill and S. Levy (NB5 6.4). Accepted, Journal of the Institute of Aeronautical Sciences.

(8) Automatic computation of nerve excitation. K. Cole (National Institutes of Health), H. Antosiewicz, and P. Rabinowitz. Accepted, Journal of the Society for Industrial and Applied Mathematics.

(9) Easily used simultaneous confidence limits for a line. W. S. Connor. Submitted to a technical journal.

(10) Time-discrete stochestic processes in arbitrary sets, with applications to processes with absorbing regions and to the problem of loops in Markof chains. D. van Dantzig. Accepted for publication (in French) in Anales de l'Institut Henri Poincaré (Paris).

(11) On the theorem of Dilworth。G.B. Dantzig (RAND) and A. J.Hoffman. To appear in "Papers on linear inequalities and related systems," Annals of Mathematics Study 38 .

(12) On a problem in the theory of mechanical quadratures. P. Davis. Accepted, Pacific Journal of Mathematics.

(13) Numerical experiments in potential theory using orthonormal functions. P. Davis and P. Rabinowitz. Submitted to a technical journal.

(14) Some Monte Carlo experiments in computing multiple integrals. P. Davis and $\mathbb{P}$. Rabinowitz. Accepted, Mathematical Tables and other Aids to Computation.

(15) Some sampling results on the power of nonparametric rests against normel alternarives. W.J.Dixon (University of Oregon) and D. Teichroew. Submitted to a technical journal. (Abstract appeared in Ann. Math. Stat. (Mar. 1954), p. 175.

(16) Comparison of theories and experiments for the hydraulic dam-break wave. R. F. Dressler. To appear in the proceedings of the Tenth General Assembly, of the International Union of Geodesy and Geophysics, held in Rome, Italy, September 1954.

(17) Heat flow in a fluid with eddying flow. W. H. Durfee (now with Operations Research office, Johns Hopkins University). Submitted to a technical journal.

(18) A comparison theorem for eigenvalues of normal matrices. K. Fan. Accepred, Pacific Journal of Mathematics. 
(19) On systems of linear inequalities. K. Fan. To appear in "Papers on linear inequalities and related systems," Annals of Mathematics Study 38 , ed. by H. W. Kuhn and A. W. Tucker.

(20) Systems of inequalities involving convex functions. Ky Fan. Submitted to a technical journal.

(21) Fully convex normed linear spaces. K. Fan and I. Glicksburg (RAND Corporation). Accepted, Proceedings of the National Academy of Sciences.

(22) An algebraic proof of the isoperimetric inequality for polygons. K. Fan, O, Taussky and J. Todd. Accepted, Journal of the Washington Ac adeny of Sciences.

(23) Asymptotic lower bounds for the fundamental frequency of convex membranes. G. E. Forsythe. Accepted, Pacific Journal of Mathematics.

(24) A comparison between the mean successive difference and the root mean square successive difference. S. Geisser. Submitted to a technical journal.

(25) A note on the normal distribution. S. Geisser. Submitted to a technical journal.

(26) Power series for $\log e^{x} e^{y} \cdot K$. Goldberg. Accepted, Duke Journal of Mathematics.

(27) A subroutine for computations with rational numbers. P. Henrici. Accepted, Journal of the Association for Computing Machinery.

(28) Addition theorems for general Legendre and Gegenbauer functions. P. Henrici. Accepted, Journal of Rational Mechanics and Analysis.

(29) On certain series expansions involving Whittaker functions and Jacobi polynomials. P. Henrici. Accepted, Pacific Journal of Mathematics.

(30) On generating functions of the Jacobi polynomials. P. Henrici. Accepted, Pacific Journal of Mathematics.

(31) On systems of distinct representatives. A. J. Hoffman and H. W. Kuhn (Bryn Mawr College). To appear in "Papers on linear inequalities and related systems, "Annals of Mathematics 5 tudy 38.

(32) Systems of distinct representatives and linear programming. A. J. Hoffman and $H$. W. Kuhn (Bryn Mawr College). To appear in the American Mathematical Monthly.

(33) The number of absolute points of a correlation. A. J. Hoffman, M. Newman, E。 G. Straus, O. Taussky. Accepted, Pacific Journal of Mathematics.

(34) Applications of extreme value theory to cobbles and boulders in gravel pits. W. C. Krumbein and J. Lieblein. Submitted to a technical journal.

(35) A proof of Hilbert's Nullstellensatz. T. S. Motzkin. Accepted, Mathematische Zeitschrift.

(36) The assignment problem. M. Motzkin. To appear in the Proceedings of the American Mathematical Society's Sixth Symposium on Applied Mathematics, held at Santa Monica City College, August 1953. 
(37) On Féjer sets in linear and spherical spaces. T. S. Motzkin and I. J. Schoenberg. Accepted, Annals of Mathematics.

(38) Pairs of matrices with property L, II. T. S. Motzkin and 0. Taussky. Accepted, Transactions of the American Mathematical Society.

(39) An alternative proof of a theorem on unimodular groups. M. Newman. Submitted to a technical journal.

(40) An identity for the coefficients of certain modular forms. M. Newman. Accepted, Journal of the London Mathematical Society.

(41) An inclusion theorem for modular groups. M. Newman. Submitted to a technical journal.

(42) Generalizations of identities for the coeficients of certain modular forms. M. Newman. Accepted, Journal of the Lond on Mathematical Society.

(43) On the existence of idencities for the coefficients of certain modular forms. M. Newman. Submitted to a technimi journal.

(44) The diophantine equation $a x^{m}-b y^{n}=c$. M. Newman. Submitted to a technical journal.

(45) The normalizer of certain modular subgroups. M. Newman. Accepted, Canadian. Journal of Mathematics.

(46) On a generalization of the normal basis in abelian algebraic number fields. M. Newman and 0. Taussky. To appear in Communications on Pure and Applied Mathematics of New York University.

(47) On asymptotic series for functions occurring in the theory of diffraction of waves by wedges. F. Oberhettinger. Submitted to a technical journal.

(48) On the Lerch zeta function. F. Oberhettinger. Accepted, Pacific Journal of Mathematics.

(49) Determinanten mit weberwiegender Hauptiagonale und die absolute Konvergenz von limearen Iterationsprozessen. A. M. Ostrowski. Accepted, Comentarii Mathematici Helvetici.

(50) On Gaus' speeding up device in the theory of single step iteration. A. M. Ostrowski. Submitted to a technical journal.

(51) On the convergence of Gaus' alternating procedure in the method of the least squares, I. A. M. Ostrowski. Submitted to a technical journal.

(52) On the comvergence of asymptotic solutions of linear differential equations. R.M. Redheffer (U,C,L,A。) and Wasow, submitted to a technical jourmal.

(53) Contributions to the theory of rakk order statistics. I. R. Savage. Submitted to a technical journal.

(54) Inequalities for probabilities associated with the multivariate normal distribution. I. R. Savage. Submitted to a technical journal. 
(55) Algebraic equations satisfied by roots of natural numbers. E. G. Straus (University of California at Los Angeles) and o. Taussky. Accepted, Pacific Journal of Mathematics.

(56) A note on group matrices. 0. Taussy. Accepted, Proceedings of the American Mathematical Society.

(57) Some computational problems in algebraic number theory. 0. Taussky. To appear in the Proceedings of the Anerican Mathematical Society Sixth Symposium on Applied Mathematics, held at Santa Monica City College, August 1953.

(58) Unimodular circulants. 0. Taussky. To appear in the I. Schur Memorial Volume to be published by Mathematische Zeitschrift.

(59) Generation and testing of pseudo-random numbers. 0. Taussky and J. Todd. Submitted to a technical journal.

(60) A direct approach to the problem of stability in the numerical solution of partial differential equations. J. Todd. To appear in the Proceedings of a Symposium on Partial Differential Equations, held at Berkeley, California, June 1955.

(61) Machine attacks on problems whose variables are permutations. C. B. Tompkins. To appear in the Proceedings of the American Mathematical Society Sixth Symposium on Numerical Analysis, held in Santa Monica, Calif., August 1953.

(62) An extension of a theorem of Dantzig's. C. Tompkins and I. Heller (George Washington University). To appear in "Papers on linear inequalities and related systems, "Annals of Mathematics Study 38.

(63) Computation of atomic levels: the spectrum of singly ionized tantulum. R. E. Trees (NBS Section 4.1), W. F. Cahill, and P. Rabinowitz. Accepted, Journal of Research, NBS.

(64) Best approximation polynomials of given degree. J. Walsh. To appear in the Proceedings of the American Mathematical Society Sixth Symposium on Applied Mathematics, held in Santa Monica, Calif., August 1953.

(65) On the asymptotic transformation of certain distributions into the normal distribution. W. Wasow. To appear in the Proceedings of the American Mathematical Society Sixth Symposium Applied Mathematics, held at Santa Monica, Calif., August 1953.

(66) Accelerating convergence of iterative processes. J. Wegstein. Submitted to a technical journal.

(67) Error bounds for eigenvalues of symmetric integral equations. $H$. Wieland $t$. To appear in the Proceedings of the American Mathematical Society Sixth Symposium on Applied Mathematics, held at Santa Monica, Calif., August 1953.

(68) On eigenvalues of sums of normal matrices. H. Wielandt. Submitted to a technical journal.

(69) National physical standards and design of experiment. W. J. Youden. To appear in Revue de L'Institut International de Statistique (The Hague). 
(70) Partially replicated latin squares. W. J. Youden and J. S. Hunter (American Cyanimid Co.). Accepted, Biometrics.

(71) On the analysis of covariance. M. Zelen. Submitted to a technical journal.

\subsection{Miscellaneous}

(1) More scientists. W. J. Youden. Submitted to a technical journal. 


\section{THE NATIONAL BUREAU OF STANDARDS}

\section{Functions and Activities}

The functions of the National Bureau of Standards are set forth in the Act of Congress, March 3, 1901, as amended by Congress in Public Law 619, 1950. These include the development and maintenance of the national standards of measurement and the provision of means and methods for making measurements consistent with these standards; the determination of physical constants and properties of materials; the development of methods and instruments for testing materials, devices, and structures; advisory services to Government Agencies on scientific and technical problems; invention and development of devices to serve special needs of the Government; and the development of standard practices, codes, and specifications. The work includes basic and applied research, development, engineering, instrumentation, testing, evaluation, calibration services, and various consultation and information services. A major portion of the Bureau's work is performed for other Government Agencies, particularly the Department of Defense and the Atomic Energy Commission. The scope of activities is suggested by the listing of divisions and sections on the inside of the front cover.

\section{Reports and Publications}

The results of the Bureau's work take the form of either actual equipment and devices or published papers and reports. Reports are issued to the sponsoring agency of a particular project or program. Published papers appear either in the Bureau's own series of publications or in the journals of professional and scientific societies. The Bureau itself publishes three monthly periodicals, available from the Government Printing Office: The Journal of Research, which presents complete papers reporting technical investigations; the Technical News Bulletin, which presents summary and preliminary reports on work in progress; and Basic Radio Propagation Predictions, which provides data for determining the best frequencies to use for radio communications throughout the world. There are also five series of nonperiodical publications: The Applied Mathematics Series, Circulars, Handbooks, Building Materials and Structures Reports, and Miscellaneous Publications.

Information on the Bureau's publications can be found in NBS Circular 460, Publications of the National Bureau of Standards (\$1.25) and its Supplement (\$0.75), available from the Superintendent of Documents, Government Printing Office. Inquiries regarding the Bureau's reports and publications should be addressed to the Office of Scientific Publications, National Bureau of Standards, Washington 25, D. C. 
<smiles>[CH]1C=C1</smiles> 